\title{
Relationship between Mood Change, Odor and Its Psychophysiological Responses in Humans in Terms of the Sensory Evaluation Spectrum
}

\author{
Yoshiaki Sugawara*, Asami Shigetho, Mai Yoneda, Tomoko Tuchiya, Hiroko Yamada, \\ Tomomi Matumura, Miki Hirano \\ Department of Health Science, Prefectural University of Hiroshima, Hiroshima, Japan \\ Email: ${ }^{\text {sugawara@pu-hiroshima.ac.jp }}$
}

Received 13 May 2015; accepted 23 June 2015; published 26 June 2015

Copyright (C) 2015 by authors and Scientific Research Publishing Inc.

This work is licensed under the Creative Commons Attribution International License (CC BY).

http://creativecommons.org/licenses/by/4.0/

(c) (i) Open Access

\section{Abstract}

How does the brain ultimately identify more than 10,000 odorants? How precisely can humans and their olfactory system detect and discriminate a great variety of odors and subtle differences in the molecular structures of a given aroma? In a series of studies, we have attempted to examine the relationship between mood change, odor and its psychophysiological responses, by focusing on the possible verbal (semantic) and non-verbal (skin temperature) changes in humans induced by smelling the fragrances of essential oils as well as linalool and its enantiomers. In our experimental design, the perceived sensory attributes in the participants can be represented by a sensory spectrograph: a bar graph whereby the mean of the impressions is plotted against the setting semantic impression descriptors. This article is an overview of our verbal (semantic) research results over the past decade as well as the non-verbal outcomes, which suggest that our tests of task-related sensory perception and skin temperature changes are useful for shedding more light on the finer nuances of odor discrimination and psychophysiological responses to odorants in humans. So, such information may provide clues to our long-standing questions mentioned above.

\section{Keywords}

Essential Oils, Linalool and Its Enantiomers, Mood Change, Psychological Responses, Sensory Test, Sensory Evaluation Spectrum

\footnotetext{
"Corresponding author.

How to cite this paper: Sugawara, Y., Shigetho, A., Yoneda, M., Tuchiya, T., Yamada, H., Matumura, T., \& Hirano, M. (2015). Relationship between Mood Change, Odor and Its Psychophysiological Responses in Humans in Terms of the Sensory Evaluation Spectrum. Psychology, 6, 965-988. http://dx.doi.org/10.4236/psych.2015.68095
} 


\section{Introduction}

Sensory evaluation is a method of measuring consciousness developed primarily in experimental psychology and mathematical psychology (Coombs, 1964; Guilford, 1954; Kling \& Riggs, 1972; Stevens, 1951; Torgerson, 1958). Sensory experiences can be reported using verbal (semantic) methods. To elucidate relationship between mood change, odor and its psychophysiological responses in humans while inhaling the fragrances of essential oils and one monoterpenoid (linalool) as well as its enantiometric isomers [(R)-(-)-, (S)-(+)- and (RS)-( \pm )-forms], the authors have endeavored to develop a sensory (verbal) measure of the perceived odor quality for a given aroma and analyze it statistically (Satoh \& Sugawara, 2003; Sugawara, 2001, 2008; Sugawara et al., 1998a, 1998b, 1999, 2000, 2003, 2006, 2008, 2009a, 2009b, 2013; Yamagata \& Sugawara, 2014).

In our experimental design, we asked the participants to complete a sensory questionnaire in which the perceptions of fragrances were evaluated using 13 contrasting pairs of adjectives. We assigned behavioral tasks to the participants. These included the Uchida-Kraepelin test as a mental arithmetic task and listening to environmental (natural) sounds as an auditory task. The sensory test was conducted twice, once before and once after the task. We then represented the sensory attributes of the perceived odors of essential oils as well as linalool and its enantiomers before and after the task via a sensory evaluation spectrum: a bar graph whereby the mean of the impressions was plotted against the semantic impression descriptors.

These tests have been carried out for the past decade and the sensory features of 21 essential oils as well as linalool and its enantiomers were settled so far (mention later). Among these, the ylangylang sensory evaluation spectrum (in which the mean of the impressions while inhaling the fragrance of ylangylang was plotted against the descriptors) was shown to be task dependent. When using the auditory task involving listening to environmental (natural) sounds, the ylangylang spectrum was found to be the reverse of the spectrum recorded when undertaking mental arithmetic task. Similar task dependent effects were found for bergamot, peppermint and sandalwood essential oils as well as linalool. These findings imply that the perceived odour quality depends on which behavioral task is assigned to the participants, if the same fragrance given to the participants. Moreover, same task-dependence of the sensory evaluation spectrum was found for $(R S)-( \pm)$-linalool. Besides, the $(R)-(-)-$ and $(S)-(+)$-forms of linalool resulted in different sensory spectra when subjects were undertaking mental arithmetic, but gave identical spectra when the auditory task was used. Based on these findings, it can be speculated that enantiomers of linalool may evoke different odour perceptions not only based on chirality but also based on behavioural tasks.

Humans can detect and discriminate a vast number of odors. The number perceived to be distinguishably different is estimated to range from a few thousand to more than ten thousand (Roderick, 1966; Firestein, 1991). Humans are capable of distinguishing even slight alterations in the structure of an odorous molecule, such as the difference between a pair of enantiomers, which possess the same molecular structure except for the chiral position. Such small molecular differences can lead to profound changes in the perceived odor quality. For instance, with the use of highly purified compounds by gas-liquid chromatography (GLC), it has been shown that (+)carvone is characterized as a caraway-like scent, while (-)-carvone as a spearmint-like herbal odor (Friedman \& Miller, 1971; Leitereg et al., 1971). Enantiomers of carvotanacetone and trans-dehydrocarvone, both synthesized from (+)-carvone, are caraway-like, whereas those prepared from $(-)$-carvone are spearmint-like (Russell \& Hills, 1971). Similarly, (+)- and (-)-linalool are petitgrain-like and lavender-like, respectively (Ohloff \& Klein, 1962).

How precisely can humans and their olfactory system detect and discriminate such a great variety of odors and such subtle differences in the molecular structures? A number of proposals and theories have been presented to explain this issue, with a variety of views involving vibrational energy levels, intermolecular interactions, and molecular size and shape (Roderick, 1966). However, no physiological theories have followed from these ideas. In 1991, a breakthrough was made by Buck and Axel, who identified the genes coding for olfactory receptors (Buck \& Axel, 1991). Since this initial discovery in rat, it has been established that the detection of odorants is mediated by a large number of G protein-coupled odorant receptors (Ors) encoded by a multigene family (Buck, 1996; Mombaerts, 1999). The number of Ors is estimated at 1000 in mouse and rat, 500 - 750 in human and 100 in fish (Zhang \& Firestein, 2002). In mammals, Ors are found in the hair-like cilia of olfactory neurons, which are located in the olfactory epithelium at the back of the nose. Thus, initial odor detection is mediated by a vast number of different odorant receptors, located at the entrance of the olfactory system in direct contact with the air, and signals of smell are transmitted to the brain. Under the assumption that the mammalian DNA contains around 100,000 genes, $1 \%$ or more of the genome is considered to be devoted to the detection of odors, 
making the Ors family the largest gene family thus far identified in mammals (Axel, 1995).

The limbic system, which is related to mood, memory, and sexual activity, is closely associated with the olfactory system and is likely to play a principal role not only in discrimination of a great variety of odors and subtle differences in the molecular structures but also in the diverse odor reaction depending on internal and extraneous conditions of the persons while inhaling fragrant ingredients. The scent of different odors is known to alter mood, alertness, and sexual arousal (Billot \& Wells, 1975; Morris, 1984; Valnet, 1982). Perfumes, room fragrances, and incense have been used for self-adornment and modification of living spaces since ancient times. The practice known as Aromatherapy, which began in France in the early 20th century, has been increasing in popularity up to the present day. In medicine, interest in the use of essential oils has grown considerably, such that essential oils are currently used worldwide for the management of chronic pain, depression, anxiety, and cognitive, sleep-, and stress-related disorders (Buchbauer \& Jirovetz, 1994; Buckle, 1999, 2004; Edge, 2003; Holmes et al., 2002; Kyle, 2006; Perry \& Perry, 2006; Price \& Price, 2007; Smallwood et al., 2001). Essential oils are now extensively utilized in the context of aromatherapy (specifically alternative medicine) and aroma wellness. The following questions arise: How does the brain prompt the range of emotional or behavioral responses that aromas often provoke? To what extent is a particular behavior or mood governed by the perception of odors?

We have attempted to examine the relationship between mood change, odor and its psychophysiological responses, by focusing on the possible verbal (semantic) and non-verbal (skin temperature) changes in humans induced by smelling the fragrances of essential oils as well as linalool and its enantiomers. In a series of our research activities, sensory evaluation has been a key component of our studies. In this article, we provide an overview of our semantic (verbal) research achievements over the past decade as well as the non-verbal (skin temperature) outcomes, which suggest that our tests of task-related sensory perception and skin temperature changes are useful for shedding more light on the finer nuances of odor discrimination and psychophysiological responses to odorants in humans. We believe that this approach has the potential to be highly informative, so that such information may provide clues to the following long-standing issues: How does the brain ultimately identify more than 10,000 odorants? How precisely can humans and their olfactory system detect and discriminate a great variety of odors and subtle differences in the molecular structures of a given aroma? How does the perception of odors usually associate with pleasant or unpleasant emotions? How does the brain prompt the range of emotional or behavioral responses that aromas often provoke? To what extent is a particular behavior or mood governed by the perception of odors?

\section{Sensory Profiling for Verbal Responses in Perceived Odor Quality in Humans}

The sensory evaluation spectrum method is first discussed in reference to one of our sensory studies (Sugawara, 2008; Sugawara et al., 2009a, 2013; Yamagata \& Sugawara, 2014), whereby the target sensory property was to determine the perceived odor quality in participants after inhalation of a given aroma on the basis of the task-dependent sensory questionnaire assessments.

Essential oils were purchased from Fleur (London, UK). Linalool was a product of Kanto Kagaku Co., Ltd. (Tokyo, Japan). To achieve the optimal concentration of each odorant for inhalation experiments, we presented a series of diluted solutions, which comprised the odorants mixed with deodorized diethyl phthalate $(1 / 1,1 / 5,1 / 10$, $1 / 50,1 / 100,1 / 1000$, and $1 / 10,000$ ), to several judges (usually five) via an inhalator consisting of a glass inhalator device and a 300-mL flask with a ground-glass stopper. The inhalator flask was loaded by applying $200 \mu \mathrm{L}$ of diluted odorant to a small strip of filter paper placed at the bottom of the flask. The flask was sealed with the ground-glass stopper. The judges were asked to give each test solution a score from 0 to 5 based on the following scale: 0 , odorless; 1 , odor barely detectable and the nature of the odor cannot be ascertained; 2 , very weak odor but the nature of the odor can be discriminated; 3 , weak odor but the odor can be readily detected; 4 , strong odor; and 5, odor so strong that it cannot be tolerated. Concentrations receiving a score of 3 or above were used for experiments. For example, we used dilutions of 1/5 for lemon, 1/10 for bergamot, cardamom, cinnamon, cypress, geranium, ho leaf/wood, juniper, lime, orange, palmarosa, sandalwood, spearmint and ylangylang, and one monoterpenoid (linalool), and 1/100 for basil, chamomile, clove, lavender, marjoram, pepper mint and rosemary. The optimal concentration of optically active linalools will be detailed later.

Incidentally, Lorig and Schwartz (1988) stated that odors act as neurophysiological stimuli by causing different perceptions, which, in turn, lead to diverse odor reactions, depending on the internal and extraneous condi- 
tions of the participants. To investigate this notion, we assigned different behavioral tasks ("extraneous conditions") to the participants. We used the Uchida-Kraepelin test as a mental arithmetic task and listening to environmental (natural) sounds as an auditory task. In the Uchida-Kraepelin test, the participant is given a sheet of paper with adjacent rows of numbers (100 numbers per row). They are asked to perform simple additions using the numbers within a row. We gave our participants 40 s to work on each row before changing to the next row (5 min total). The auditory task (5 min total) consisted of sitting on a chair and listening to natural sounds, such as birds singing and the murmuring of a small stream. This was accomplished via headphones connected to a compact disc player.

As a measure (sensory profiling) of the perceived odor quality after inhalation of a given aroma, we asked the participants to complete a sensory questionnaire assessment (Sugawara, 2008; Sugawara et al., 2009a, 2013; Yamagata \& Sugawara, 2014). In the questionnaire, aroma perception was evaluated using 13 descriptors comprising the following pairs of contrasting adjectives: fresh-stale, soothing-activating, airy-heavy, plain-rich, natural-unnatural, elegant-unrefined, soft-strong, pleasant-unpleasant, warm-cool, comfortable-uncomfortable, woodsy-not woodsy, floral-peppery, lively-dull.

The 13 descriptors were scored on an 11-point scale $(-5$ to +5$)$, with 0 as the middle score. There were no symbolic representations associated with the numbers, similar to the Likert scale (Linkert, 1932). We conducted the sensory test twice, before and after the task. We evaluated the differences between the pre- and post-task scores (post-task scores minus pre-task scores) for each of the descriptors using Student's $t$-tests. The mean difference in the score of each descriptor was plotted against the 13 descriptors, producing a sensory evaluation spectrum. The statistical significance of each descriptor was marked and scored as follows: a score was given an * (asterisk) and a significance score of 1 if the difference was significant such that $p<0.05$; a \pm and a significance score of 0.5 if the difference was significant such that $p=0.05-0.1$; and no symbol and a significance score of 0 if the difference was not significant such that $p \geq 0.1$. The sum of these scores was the total significance score $=\Sigma_{\mathrm{i}=1}^{13}$ (significance score of descriptor) $)_{\mathrm{i}}$. We used this value as an index of whether the relevant sensory spectrum could be considered to be statistically significant across the spectrograph (Sugawara, 2008; Sugawara et al., 2009a, 2013; Yamagata \& Sugawara, 2014). To confirm this, we used a sign test with $n=13$, corresponding to the number of descriptors used in our sensory test. We found that the spectra could be expected to reach significance $(p<0.05)$ when the number of descriptors regarded as significant at a probability value of $p<0.05$ (according to the $t$-test) was greater than 10 out of the 13 descriptors. In contrast, when this value was less than 3 , the null hypothesis could be rejected.

In the verbal tests so far examined, we were able to establish appropriate parameters for assessing the sensory attributes of the following 21 essential oils, and one monoterpenoid (linalool) and its enantiometric isomers as a function of the two behavioral tasks (mental arithmetic and auditory) (Table 1): basil (Ocimum basilicum), bergamot (Citrus bergamia), cardamom (Elettaria cardamomum), chamomile (Matricaria chamomilla), cinnamon (Cinnamomum zeylanicum), clove (Syzygium aromaticum), cypress (Cupressus sempervirens), geranium (Pelargonium graveolens), ho leaf/wood (Cinnamomum camphora), juniper (Juniperus communis), lavender (Lavandula angustifolia), lemon (Citrus limon), lime (Citrus latifolia), marjoram (Origanum majorana), orange (citrus sinensis), palmarosa (Cymbopogen martini), peppermint (Mentha piperita), rosemary (Rosmarinus officinalis), sandalwood (Santalum album), spearmint (Mentha spicata) and ylangylang (Cananga odorata).

To this end, 1144 participants formed the sensory test panel. Among these, 55 were male students from Hiroshima University ranging in age from 18 to 24 years. The remaining participants were female students at Hiroshima University, Prefectural University of Hiroshima (formerly Hiroshima Prefectural Women's University, but renamed as of April 1, 2005) and Suzugamine Women's College, ranging in age from 18 to 22 years. Thus, the proportion of male participants was only about 5\%. Each participant completed one sensory profile only. The detailed number of participants for each sensory profile can be found in Table 1.

\section{Sensory Profiles of Lemon and YlangYlang Essential Oils and Linalool as a Function of Behavioral Task (Extraneous Condition Assigned to the Participants)}

We employed a sensory evaluation spectrum as a measure (sensory profiling) of the perceived odor quality in participants after inhalation of a given aroma on the basis of the task-dependent sensory questionnaire assessments. It is a bar graph in which the mean of the pre-post task difference between the score of post-task inquiry 
Table 1. Summary of the total significance scores (see text) resulting from a statistical analysis of verbal (semantic) responses to the fragrances of 21 essential oils and linalool as well as its enantiometric isomers, for which semantic questionnaire assessments were conducted as a function of two behavioral tasks (i.e., mental arithmetic and auditory task).

\begin{tabular}{|c|c|c|}
\hline \multicolumn{3}{|c|}{$\begin{array}{l}\text { The obtained total significance score for a given aroma in relation to the task } \\
\text { assigned to the participants with the number of participants in parenthesis }\end{array}$} \\
\hline \multirow[b]{2}{*}{ Odorant } & \multicolumn{2}{|c|}{ Task assigned to the participants } \\
\hline & $\begin{array}{c}\text { Mental } \\
\text { arithmetic }\end{array}$ & $\begin{array}{c}\text { Auditory } \\
\text { task }\end{array}$ \\
\hline \multicolumn{3}{|l|}{ (1) Essential oils } \\
\hline Basil & $5.0(n=22)$ & $0.0(n=22)$ \\
\hline Bergamot & $2.0(24)$ & $2.5(18)$ \\
\hline Cardamon & $0.0(24)$ & $0.0(23)$ \\
\hline Chamomile & $0.5(21)$ & $1.0(23)$ \\
\hline Cinnamon & $2.0(36)$ & $8.5(41)$ \\
\hline Clove & $0.5(20)$ & $2.0(19)$ \\
\hline Cypress & $0.5(20)$ & $1.0(18)$ \\
\hline Geranium & $5.5(21)$ & $2.5(30)$ \\
\hline Ho leaf/wood & $1.0(19)$ & $2.5(18)$ \\
\hline Juniper & $6.5(17)$ & $6.5(19)$ \\
\hline Lavender & $0.0(20)$ & $1.5(21)$ \\
\hline Lemon & $8.0(43)$ & $7.0(41)$ \\
\hline Lime & $6.0(24)$ & $1.0(18)$ \\
\hline Marjoram & $2.0(21)$ & $1.0(30)$ \\
\hline Orange & $5.0(22)$ & $1.0(30)$ \\
\hline Palmarosa & $2.0(18)$ & $3.5(21)$ \\
\hline Peppermint & $6.0(20)$ & $3.5(23)$ \\
\hline Rosemary & $1.0(20)$ & $0.5(18)$ \\
\hline Sandalwood & $2.0(21)$ & $6.5(22)$ \\
\hline Spearmint & $4.5(18)$ & $3.0(18)$ \\
\hline Ylangylang & $2.0(19)$ & $5.5(24)$ \\
\hline \multicolumn{3}{|l|}{$\begin{array}{l}\text { (2) Linalool and } \\
\text { its enantiometric isomers }\end{array}$} \\
\hline Linalool & $5.5(20)$ & $5.0(22)$ \\
\hline$(R S)-( \pm)$-linalool & $4.0(18)$ & $6.5(21)$ \\
\hline$(R)-(-)-$ linalool & $4.5(23)$ & $7.0(24)$ \\
\hline$(S)-(+)$-linalool & $3.5(26)$ & $4.0(23)$ \\
\hline
\end{tabular}

and pre-task inquiry (post minus pre) was plotted against the 13 impression descriptors. Figure 1 shows several representative spectrographs. In each of these, if the descriptors regarded as significant by $t$-test have a positive value and are shown above the horizontal axis, this signifies a positive (or favorable) correlation between the fragrance of a given aroma and the type of task, according the positive descriptors (i.e., "fresh,” “airy,” “elegant,” "pleasant," “comfortable,” etc.). If negative values appear below the axis, this suggests an unfavorable (negative) correlation between the fragrance and the type of task in terms of the negative descriptors (i.e., "stale," "heavy," 
(a) Lemon/ Mental arithmetic

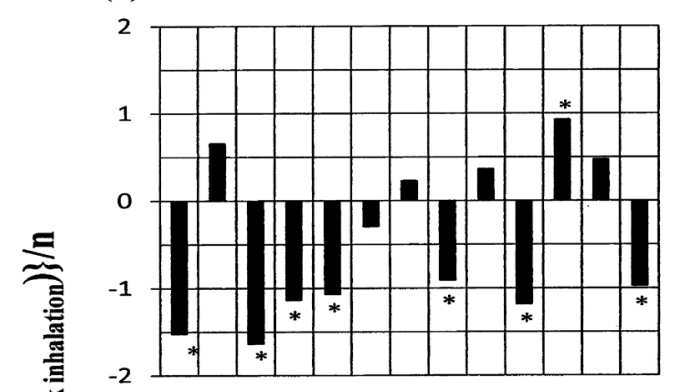

(b) Ylang ylang/ Mental arithmetic

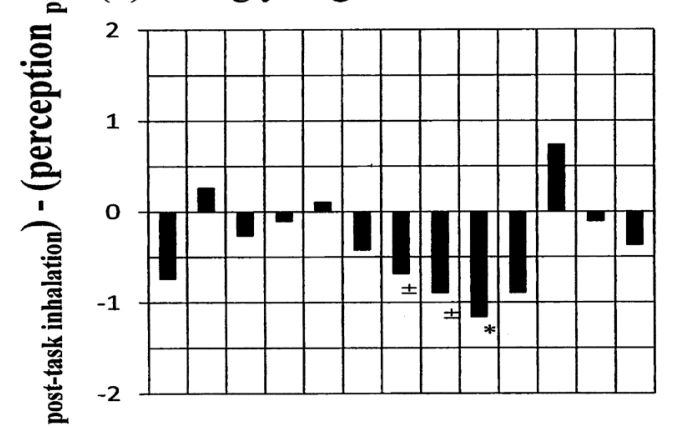

(c) Linalool/ Mental arithmetic

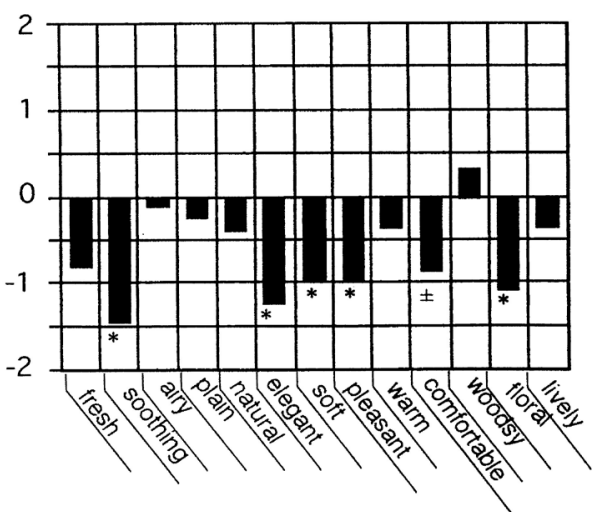

(d) Lemon/ Auditory task

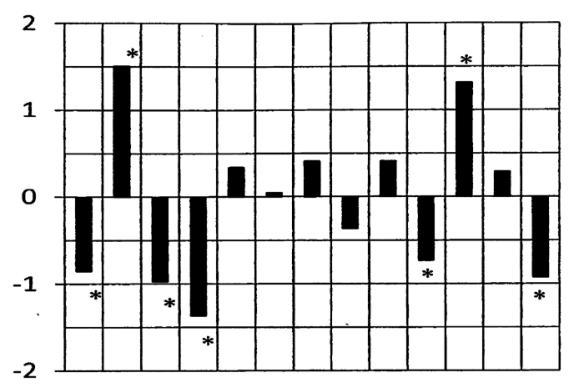

(e) Ylang ylang/ Auditory task

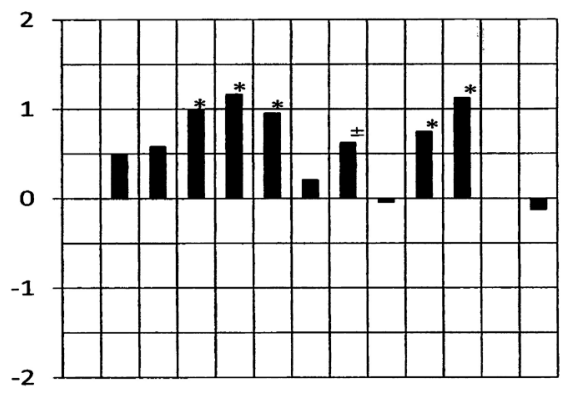

(f) Linalool/ Auditory task

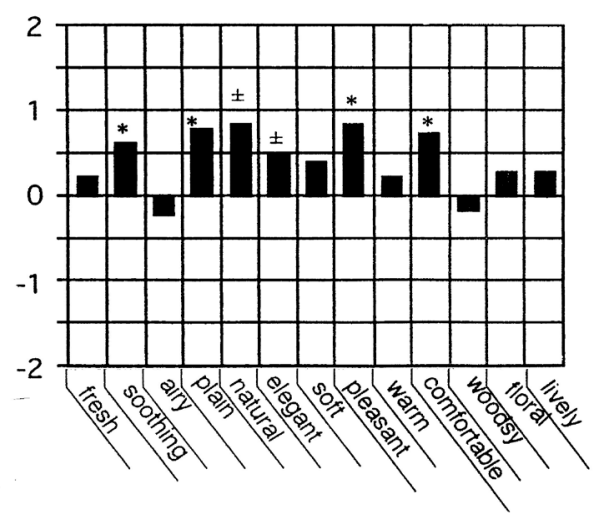

Figure 1. Sensory spectra of essential oils of lemon and ylangylang as well as linalool as a function of two behavioral tasks. A sensory test was conducted twice before and after the task assigned to the participants, in which aroma perception was evaluated by 13 impression descriptors consisting of contrasting pairs of adjectives. The pre-post task difference in the score of each of the impression descriptors is plotted on the ordinate as a bar graph. The statistical significance evaluated by $t$-test of each descriptor was marked with a single asterisk $\left(^{*}\right)$ if the pre-post impression difference was regarded significant with $p<$ 0.05 , \pm if regarded significant with $p=0.05-0.1$, and unmarked if $p \geq 0.1$. The number of participants was (a) 43 , (b) 19 , (c) 20, (d) 41, (e) 24 and (f) 22.

“unrefined,” “unpleasant,” “uncomfortable,” etc.). Figure 1 contains a summary of the responses to inhalation of the fragrances of essential oils of lemon and ylangylang, and linalool.

As seen in Figure 1, the sensory spectrograph obtained after inhalation of lemon in association with the mental arithmetic task indicates an unfavorable (downward or negative) correlation between the fragrance and the task (Figure 1(a)). On the other hand, the spectrograph after inhalation of lemon in association with the auditory task denotes that half of the significant descriptors were positive and the other half negative (Figure 1(d)).

In turn, negative (unfavorable) correlation similar to the spectrograph for lemon/mental arithmetic (Figure 1(a)) was in view in the spectrograph of ylangylang/mental arithmetic (Figure 1(b)). In contrast, positive (favorable) correlation between the fragrance and the task was obvious in the spectrograph of ylangylang/auditory 
task (Figure 1(e)). This means that the sensory attribute after inhalation of the fragrance of ylangylang produced opposite (contrasting) signs during the two behavioral tasks in terms of the sensory evaluation spectrum (Figure 1(b) and Figure 1(e)). One was representing downward spectrograph in relation to the mental arithmetic task and the other representing upward spectrograph in association with the auditory task. In the Figure, it was apparent that similar opposing effects for the two behavioral tasks were found for linalool (Figure 1(c) and Figure 1(f)). These imply that different behavioral tasks (or different "extraneous conditions") might influence the perceived odor quality of a given aroma after inhalation. In other words, that the finer nuances were visible in each spectrum when observed as a function of the different behavioral tasks indicated that this method of sensory profiling could be practical for assessing odor perception in participants.

However, none of the spectra reached statistical significance among the 50 cases contained in Table 1, including the cases shown in Figure 1. In our experimental design, in each spectrograph (as shown in Figure 1), the statistical significance of each descriptor was marked and scored as follows: * (asterisk) and significance score of 1 if the difference was significant such that $p<0.05$; \pm and a significance score of 0.5 if the difference was significant such that $p=0.05-0.1$; and no symbol and a significance score of 0 if the difference was not significant such that $p \geq 0.1$. The sum of these scores provided a total significance score $=\Sigma^{13}{ }_{i=1}$ (significance score of descriptor) $)_{\mathrm{i}}$. Total significance scores were calculated by simple addition of the statistical significance scores marked on the individual descriptors in the relevant spectrum. In Figures 1(a)-(f), we obtained total significance scores of 8.0 for lemon/mental arithmetic, 7.0 for lemon/auditory task, 2.0 for ylangylang/mental arithmetic, 5.5 for ylangylang/auditory task, 5.5 for linaloo/mental arithmetic, and 5.0 for linalool/auditory task. Table 1 shows a summary of the obtained total significance scores for the 21 essential oils as well as linalool and its enantiomers in relation to the two behavioral tasks (mental arithmetic and auditory task). Here the total significance scores were a convenient index for evaluating whether the relevant spectrographs were statistically significant. This issue has been the subject of our studies (Sugawara, 2008; Sugawara et al., 2009a; Yamagata \& Sugawara, 2014). We finally employed a sign test with $n=13$, corresponding to the number of descriptors used in our sensory test. We found that, for a sign test with $n=13$, the resulting sensory spectra would be significant (at $p<0.05$ ) when the number of descriptors regarded as significant at a probability value of $p<0.05$ according to the $t$-test was greater than 10 (out of 13 descriptors). In contrast, when this value was less than 3 , the null hypothesis could be rejected.

As demonstrated in Table 1, we found no sensory spectra with total significance scores of $>10$ among the 50 cases examined, although 8.5, which was derived from the spectrograph of cinnamon/auditory task, was the largest value. Regardless, the resulting sensory spectra warranted particular interest (Figure 1).

\section{Sensory Profiles of Enantiometric Isomers of Linalool: Discrimination between Enantiomers in Terms of the Sensory Evaluation Spectrum as a Function of Behavioral Task}

Without regard to our statistical defects associated with the significance of the sensory spectra mentioned in the previous section, in this section, we describe our research attempts on odor discrimination of enantiomers of linalool, quantified with the sensory evaluation spectrum and observed as a function of behavioural task (Sugawara, 2001, 2008; Sugawara et al., 2000, 2013).

Optically active linalools $[(R)-(-)-,(S)-(+)-$ and $(R S)-( \pm)-$ forms] (Figure 2$)$ were obtained by repeated flash column chromatography on silica gel (solvent: hexane/ethyl acetate, 9:1, v/v) of lavender oil, coriander oil and commercial linalool (see Sugawara et al., 2000 for details). For example, lavender oil (2.0 g) was subjected to flash chromatography on silica gel to yield linalool (439 mg), and its spectral (EI-MS, IR and ${ }^{1} \mathrm{H}-\mathrm{NMR}$ ), chromatographic (analytical thin-layer chromatography; TLC, Merck 60 GF254 silica gel plate), and gas liquid chromatography (GLC; CP-cyclodextrin- $\beta$-236M-19) behaviour was compared with those of authentic specimens (kindly supplied by Dr. Y. Hiraga of Hiroshima University, Japan). The linalool was identified as $(R)-(-)$-linalool based on co-GLC analysis with an authentic $(R)$-form and was found to have a specific rotation of $[\alpha]_{\mathrm{D}}=-15.1^{\circ}$, a $97.0 \%$ purity on GLC and a $21.95 \%$ total yield.

Using the same method, $(S)-(+)$-linalool was obtained from coriander oil, with a $32.9 \%$ total yield, a content of the $(S)$-form of $88.3 \%$ and $(R)$-form $11.7 \%$ on GLC, and $[\alpha]_{\mathrm{D}}=+17.4^{\circ}$. Similarly, $(R S)-( \pm)$-linalool with a $74.5 \%$ total yield, a content of the (S)-form of $49.1 \%$ and $(R)$-form $50.9 \%$ on GLC, and $[\alpha]_{\mathrm{D}}=0^{\circ}$ was re-purified from commercial linalool. 


\section{$R S$-( \pm )-linalool $\quad R$-(-)-linalool $\quad S$-(+)-linalool}

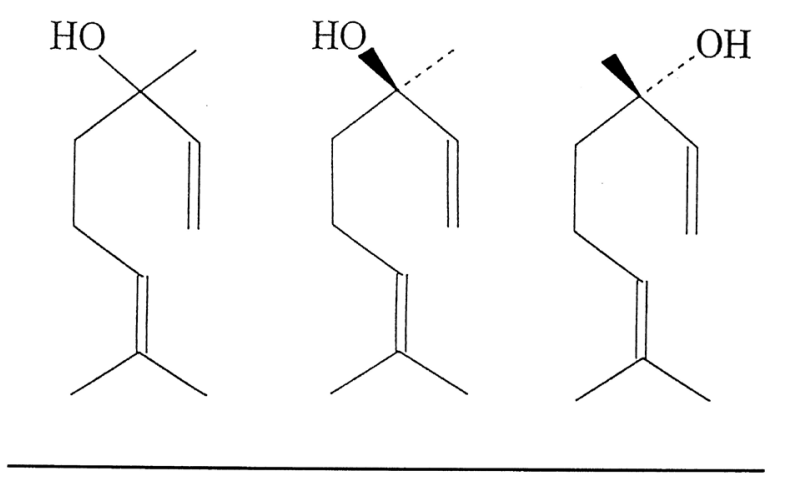

Figure 2. Formula of enantiometric isomers of linalool.

We used $20 \mathrm{mg} / \mathrm{mL}$ solutions of the enantiomers for sensory profiling because this concentration was rated as at least level 3 ("weak odour but the odour can be readily detected") by the judges when they were presented with $50,20,10,1$ and $0.1 \mathrm{mg} / \mathrm{mL}$ solutions. The sensory spectra obtained using the optically active linalools in combination with the two behavioral tasks are summarized in Figure 3. Since $(R S)$-( \pm )-linalool was purified from commercial linalool and identified as a racemic mixture of the $(R)$-form $(50.9 \%)$ and $(S)$-form $(49.1 \%)$ with $[\alpha]_{\mathrm{D}}=0^{\circ}$, we used $(R S)-( \pm)$-linalool as a reference. The sensory evaluation spectra for purified linalool (Figure 3(a) and Figure 3(d)) showed practically the same task-dependence of perception as the commercial linalool (Figure 1(c) and Figure 1(f)). The total significance score of purified linalool was 4.0 for the mental arithmetic task (Figure 3(a)) and 6.5 for the auditory task (Figure 3(d)). This was in good agreement with the scores obtained using the commercial linalool, which were 5.5 with mental arithmetic (Figure 1(c)) and 5.0 with the auditory task (Figure 1(f)).

Figure 3 shows the sensory evaluation spectra from participants inhaling either $(R)-(-)$ - or $(S)-(+)$-forms of linalool while undertaking the mental arithmetic or auditory tasks. $(R S)-( \pm)$-linalool was used as a reference. After mental arithmetic (Figures 3(a)-(c), left hand side) the spectra showed negative values, indicating that the perceived odour quality of $(R)-(-)$ - and $(S)-(+)$-linalools and the racemic mixture of the $(R)$ - and $(S)$-forms was less favourable after the task. After the auditory task (Figures 3(d)-(f), right hand side) the spectra showed mostly positive values. Thus, the spectra were completely reversed after the auditory task compared with the mental arithmetic task. Furthermore, a closer examination of the spectra obtained for the auditory task made it obvious that the sensory spectrum of $(R)-(-)$-linalool was identical to that of the reference $(R S)$-( \pm -linalool, but not to that of $(S)-(+)$-linalool, for which half of the significant descriptors were positive and the other half negative.

It should be noted afresh that none of the spectra shown in Figure 3 reached statistical significance, because the total significance scores were all $\leq 10$ (Table 1). However, given these findings and the fact that Ohloff and Klein (1962) suggested (+)- and (-)-linalool are petitgrain-like and lavender-like, respectively, it is interesting to speculate that different enantiomers of linalool may evoke distinct odour perception in a task-dependent manner.

\section{Multi-Channel Skin Thermometer Study: Assessing the Statistical Significance of the Sensory Evaluation Spectra}

Here, we describe the results of our multi-channel skin thermometer study. Because we considered a variety of strategies for addressing statistical defects associated with the significance of the sensory spectra. Conclusively, we found that multi-channel skin thermometer data might complement the statistical defects of the relevant sensory spectra.

Emotional excitement or apprehension is known to induce a slight increase in skin temperature (Elam \& Wallin, 1987; Oka et al., 2001, 2008; Yamakoshi et al., 2007; Ziegler \& Cash, 1938). As the perception of and 
(a) (RS)-( \pm )-linalool/ Mental arithmetic

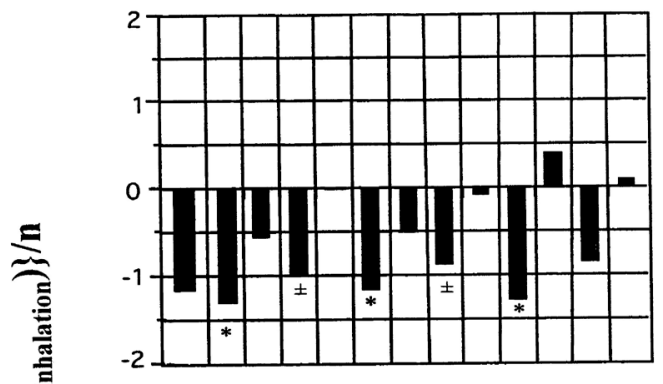

(b) (R)-(-)-linalool/Mental arithmetic

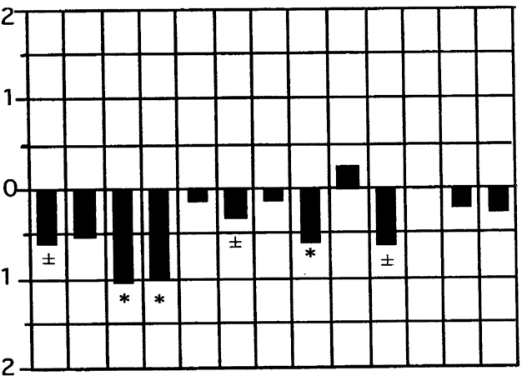

(c) $(S)-(+)$-linalool/ Mental arithmetic

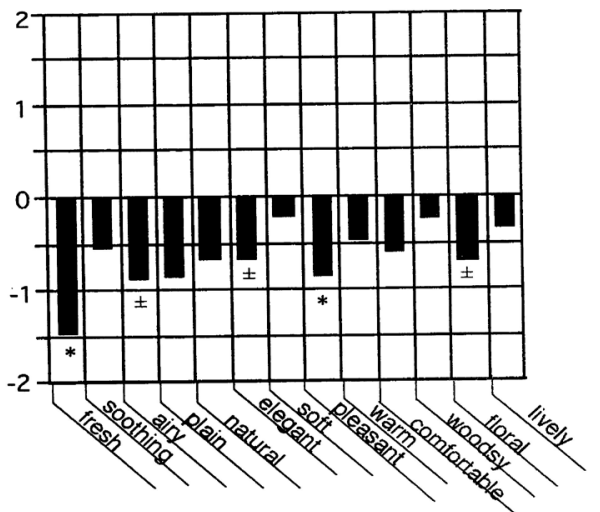

(d) (RS)-( \pm )-linalool/ Auditory task

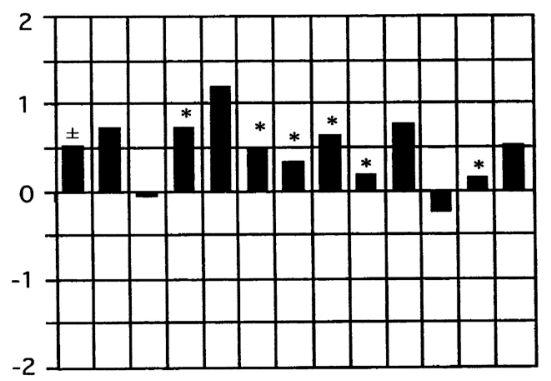

(e) (R)-(-)-linalool/ Auditory task

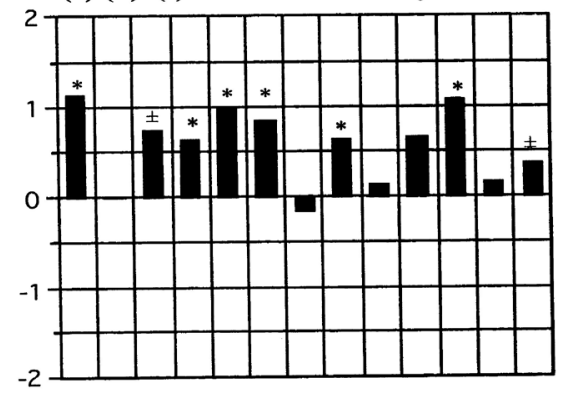

(f) (S)-(+)-linalool/ Auditory task

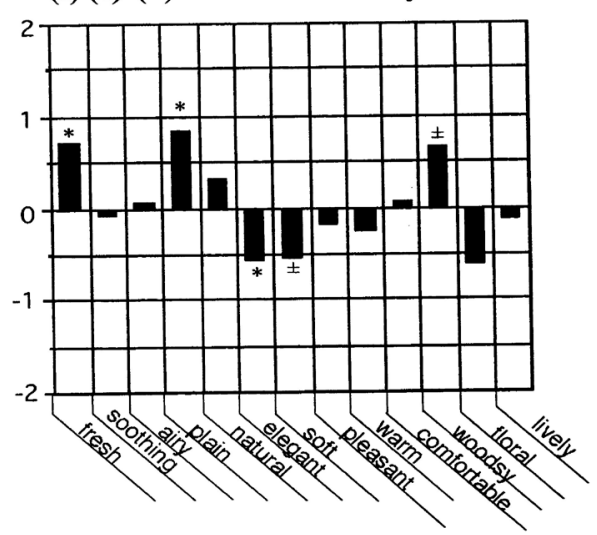

Figure 3. Sensory spectra of enantiomers of linalool $[(R S)-( \pm)-,(R)-(-)-$ and $(S)-(+)$-forms] as a function of two behavioral tasks. Redrawn from Sugawara et al. (2013). (a) (RS)-( \pm )-linalool, (b) $(R)-(-)$-linalool and (c) (S)-(+)-linalool when the subjects undertaking mental arithmetic; and (d) (RS)-( \pm -linalool, (e) $(R)-(-)$-linalool and (f) (S)-(+)-linalool while undertaking the auditory task. Concentration of enantiomer was every $20 \mathrm{mg} / \mathrm{mL}$ (in diethyl phthalate), which was loaded and moistened in an inhalator (300 mL vol.) by applying $200 \mu \mathrm{L}$ of each solution. The number of participants was (a) 18; (b) 23; (c) 26; (d) 21; (e) 24 and (f) 23.

response to odors are intimately related to both emotional expression and genesis of emotion, skin temperature changes can serve as an effective index for the study of the relationship between odor and its emotional and physiological responses in humans.

Multi-channel skin thermometer measurements were conducted in a climatic chamber maintained at $20^{\circ} \mathrm{C}$ and $60 \%$ relative humidity. A total of 415 participants completed the study. Participants were all female students at Prefectural University of Hiroshima, ranging in age from 18 to 22 years. The procedure was first explained to each participant, who were then encouraged to relax and allowed to rest quietly for 5 min before the test began. None of the participants were suffering from any chronic diseases, nasal congestion, or upper respiratory tract infections, and no participants were taking any medication, remedies, or contraceptive pills. To avoid the potential confounding effects of hormonal profile and physiological status, female participants did not participate in 
the study during menses. Ambient noise was kept at a low level (30 - $40 \mathrm{dBA}$ ) during the experiments.

We recorded skin temperature (fingertip) using a thermometer (Anritsu AM-7052; Anritsu Meter Co., Tokyo, Japan) equipped with a multi-channel data collector. Thin surface thermistors $(2 \times 10 \mathrm{~mm})$ were used as sensors. They were attached with adhesive tape to the tips of all fingers on the left hand and to the palm at the base of the first finger of the left hand.

Various parts of the body have different temperatures that undergo circadian fluctuations. Thus, we conducted a pilot experiment in which the thermistors were affixed to the left cheek, left earlobe, forehead, tip of the left first finger, left palm (at the base of the first finger), and back of the left hand (at the base of the first finger). We used an odorless blank as a negative control. The skin temperature curve obtained from the tip of the left first finger and left palm showed a small but significant increase after odor inhalation, while practically no change was observed at the other measurement points (Sugawara \& Kawasaki, 2000). Therefore, we developed a multi-channel thermometric technique by which skin temperature could be measured from the fingertips and palm of the left hand (Satoh \& Sugawara, 2003; Sugawara et al., 2006, 2008, 2009a, 2013).

All data were stored on a personal computer at a sampling rate of $15 \mathrm{~s}$ via an A/D converter connected to the multi-channel thermometer. This allowed summation of the data from each channel every $15 \mathrm{~s}$ so that a single temperature curve could be obtained for the six measurement points. The experimental protocol was as follows: (1) inhalation of the odorless blank (total inhalation: 3 min; presence of the odorless blank: $30 \mathrm{~s}$ ), (2) inhalation of the essential oil before the task (total: $5 \mathrm{~min}$, presence of the fragrance: $1 \mathrm{~min}$ ), (3) $5 \mathrm{~min}$ of the task, (4) post-task inhalation of essential oil (total: $5 \mathrm{~min}$; presence of the fragrance: $1 \mathrm{~min}$ ), and (5) inhalation of the odorless blank (total: 3 min; presence of the odorless blank: $30 \mathrm{~s}$ ).

For each experimental run, we constructed a temperature profile (bar chart) by integrating the temperature curves (per minute) with each section of the skin temperature measurement protocol (mean temperatures at 1-minute intervals). We were then able to calculate the net skin temperature change between the presentation of the odorless blank and the presentation of the target fragrance: $\left(\mathrm{T}^{\mathrm{MMA}}{ }_{\text {odor }}-\mathrm{T}^{\mathrm{MMA}}{ }_{0}\right) / \mathrm{T}^{\mathrm{MMA}}{ }_{0}$, where $\mathrm{T}^{\mathrm{MMA}}$ odor is the mean minute-based average temperature during odor presentation, and $\mathrm{T}^{\mathrm{MMA}}$ is the intensity during the presentation of the odorless blank.

Figure 4 shows a representative sample of the skin temperature results from participants who inhaled lemon before and after the auditory task. As shown in Figure 4(a) (individual curves) and Figure 4(b) (summation), the skin temperature curves showed a small but considerable change during odor presentation. However, there was considerable individual variation between trials in an experimental run. Therefore, for each trial, the minutebased mean average temperature was calculated for the different odor presentation periods (Figure 4(c)). On the basis of the minute-based temperature profile, the net change in skin temperature for each experimental run was calculated according to the formula described above. This method produced the results shown in Figure 4(d) and Figure 4(e). In Figure 4(d), the cases showing an increase in skin temperature after the task are plotted in the left diagram, while those showing a decrease are represented in the right diagram. Figure 4(e) shows the overall mean values of the net temperature changes between pre- and post-task inhalations.

Similarly, Figure 5 shows an example of the skin temperature results from participants who inhaled palmarosa either in relation to mental arithmetic (Figure 5(a)) or the auditory task (Figure 5(b)). As shown in Figure 5(a) and Figure 5(b), for each trial, cases with an increase in skin temperature after the task are plotted in the left diagram, while those showing a decrease are represented in the middle diagram. A bar graph on the right side of Figure 5 contains the overall (summarized) mean values of the net intensity changes between pre- and post-task inhalations. Figure 5(a) and Figure 5(b) clearly demonstrate that the temperature response to palmarosa occurred in opposite directions for the two behavioral tasks: we observed a significant increase in skin temperature between pre- and post-task inhalations for mental arithmetic (at $p<0.01$ ): $\left|t_{0}\right|=3.555 \geq t_{\text {d.f. }}$ (d.f. $=$ $10, p=0.01)=3.106$ (Figure 5(a)), and a tendency for skin temperature to decrease for the auditory task, although this change did not reach statistical significance (Figure 5(b)).

Similar to palmarosa, the temperature response to inhalation of lemon occurred in opposite directions for the two behavioral tasks: we observed a significant decrease in skin temperature between the pre- and post-task inhalations for mental arithmetic (at $p<0.05)$ : $\left|t_{0}\right|=2.585 \geq t_{\text {d.f. }}($ d.f. $=12, p=0.05)=2.179$, and a significant increase in skin temperature for the auditory task (at $p<0.05$ ): $\left|t_{0}\right|=2.655 \geq t_{\text {d.f. }}($ d.f. $=13, p=0.05)=2.145$, as shown in Figure 4.

Also, we observed a significant increase in skin temperature for basil/mental arithmetic (at $p<0.05$ ): $\left|t_{0}\right|=$ $2.173 \geq t_{\text {d.f. }}($ d.f. $=16, p=0.05)=2.110$, and juniper/mental arithmetic (at $\left.p<0.01\right):\left|t_{0}\right|=3.587 \geq t_{\text {d.f. }}($ d.f. $=11$, 
(a)

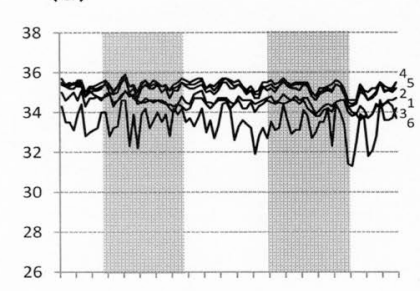

(b)
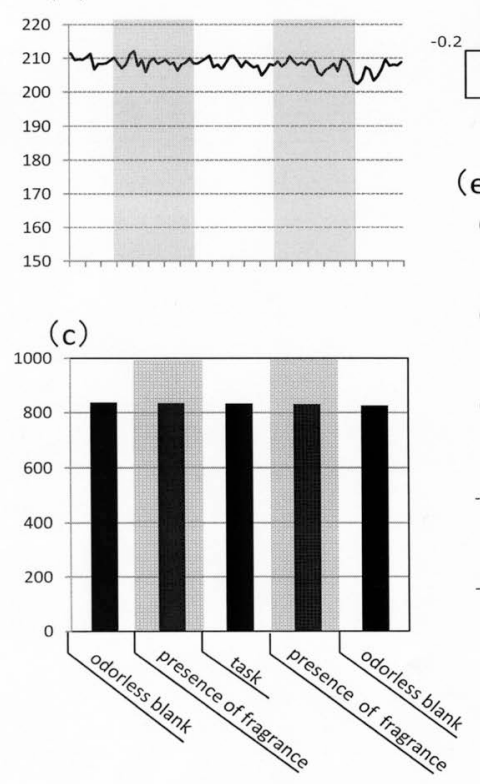

(d)

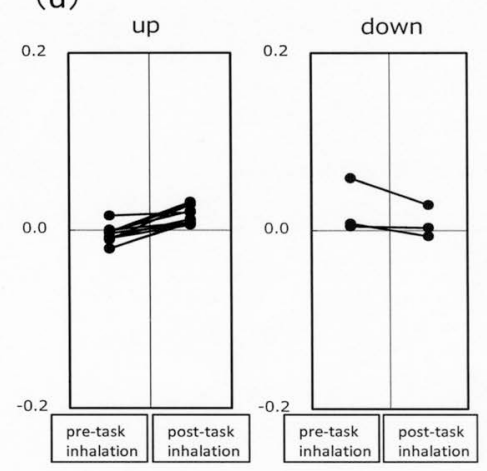

(e)

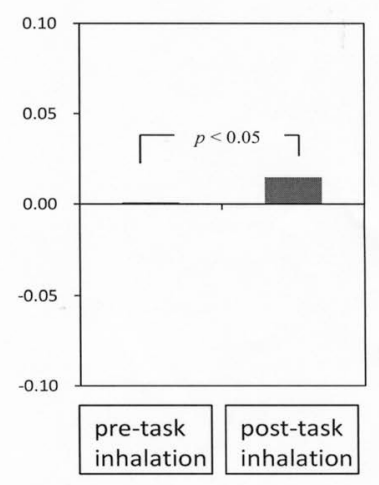

Figure 4. The observed skin temperature changes following inhalation of lemon in association with the auditory task. The numbers assigned to the graph represent the sensor spots on the left hand: 1 , the tip of the thumb; 2 , the tip of the first finger; 3 , the tip of the second finger; 4 , the tip of the third finger; 5 , the tip of the fourth finger, and 6 , the palm. There were 20 participants for lemon/auditory task.

$p=0.01)=3.055$.

Figure 6 shows a representative example of our attempts to combine the obtained fingertip skin temperature results with the associated sensory evaluation spectra. Figure 6 is a summary of the verbal (sensory evaluation spectrum) and non-verbal (skin temperature changes) responses of inhaling the fragrances of lemon, palmarosa, basil, and juniper. In the Figure, the perceived sensory attributes are displayed according to the sensory evaluation spectrum and the associated changes in skin temperature, both as a function of the two behavioral tasks (mental arithmetic and the auditory)

For the data in Figure 6, the practical potentialities of the skin temperature data for the evaluation of statistical significance might complement any statistical defects associated with the sensory spectrographs, even if the sensory spectra were not statistically significant. Moreover, the subtle differences between the two behavioral tasks could be viewed in terms of verbal (sensory spectrum) and non-verbal (fingertip skin temperature) changes as a function of the two behavioral tasks. In other words, the combination of non-verbal with verbal data might be highly informative, not only for studying the psychophysiological responses of essential oil fragrances, but also for examining the relationship between odor and its olfactory discrimination and responses in humans.

\section{Verbal (Sensory Evaluation Spectrum) and Non-Verbal (Skin Temperature Change) Endpoints of Inhaling Essential Oils Fragrances as a Function of Behavioral Task}

As our skin temperature measurements were proceeded, we narrowed our focus to involve only the following 12 
(a) Palmarosa/ Mental arithmetic

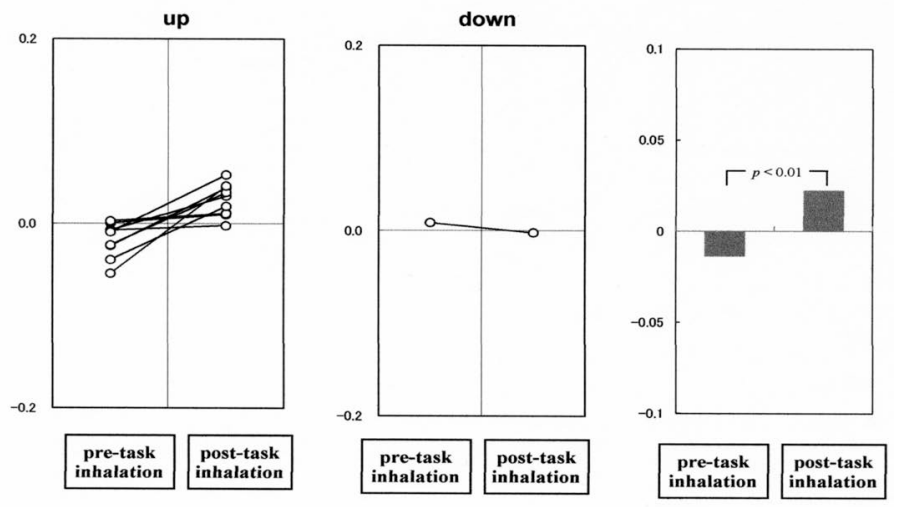

(b) Palmarosa/ Auditory task
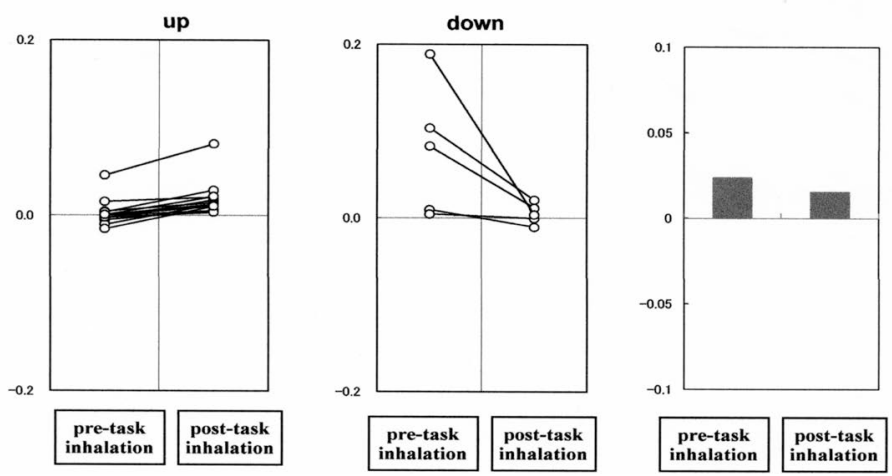

Figure 5. Skin temperature changes following inhalation of palmarosa as a function of two behavioral tasks. We calculated the net intensity change in skin temperature (see text) between pre- and post-task inhalations with respect to the odorless blank and the target fragrance in each trial. In the line segment graph, changes in net intensity are connected by a solid line for each participant in each experimental trial. Cases in which we observed upward skin temperature changes are plotted on the left, while those with a downward tendency are shown in the middle panels. The summarized mean values of net intensity changes obtained from pre- and post-task inhalations are depicted in a bar graph on the right. (a) There were 11 participants for palmarosa/mental arithmetic; and (b) 18 for palmarosa/auditory task.

essential oils: basil, bergamot, cardamom, cinnamon, juniper, lemon, orange, palmarosa, peppermint, sandalwood, spearmint and ylangylang. We also used a multi-channel skin thermometer to measure changes associated with the other essential oils (bergamot, cardamom, cinnamon, orange, peppermint, sandalwood, spearmint and ylangylang) without mentioned in the previous section. Figure 7 shows a summary of the obtained verbal (sensory evaluation spectrum) and non-verbal (skin temperature changes) data in relation to the two different behavioral tasks.

As clearly shown in Figure 7, the inhalation of the essential oils of bergamot, cardamom, cinnamon, orange, peppermint, sandalwood, spearmint, and ylangylang seemed to induce a decrease in skin temperature for the two behavioral tasks. Meantime, we observed a significant decrease in skin temperature between pre- and post-task inhalations for sandalwood/auditory task (at $p<0.05$ ): $\left|t_{0}\right|=2.318 \geq t_{\text {d.f. }}($ d.f. $=19, p=0.05)=2.086$ and spear$\operatorname{mint} /$ mental arithmetic (at $p<0.01$ ): $\left|t_{0}\right|=4.153 \geq t_{\text {d.f. }}$ (d.f. $\left.=16, p=0.01\right)=2.898$.

In this way, the verbal and non-verbal performance associated with the 12 target odors were unified in relation to the two behavioral tasks. The unified 24 odor-task combinations (the 12 target odors in relation to the two tasks) are summarized in Figure 6 and Figure 7. Based on the relationship between verbal and non-verbal responses of the 12 target odors during the two tasks, we made an attempt to classify the obtained 24 odor-task combinations into three categories: 1) the first category (Figure 6(a)), which included lemon and palmarosa, elicited task-dependent dual changes in fingertip skin temperature; 2) the second category (Figure 6(b)), which included basil and juniper, not only elicited an increase in skin temperature, but also the increased sensory spectra in a non-task dependent fashion; and 3) the third category (Figure 7), which included bergamot, cardamom, 


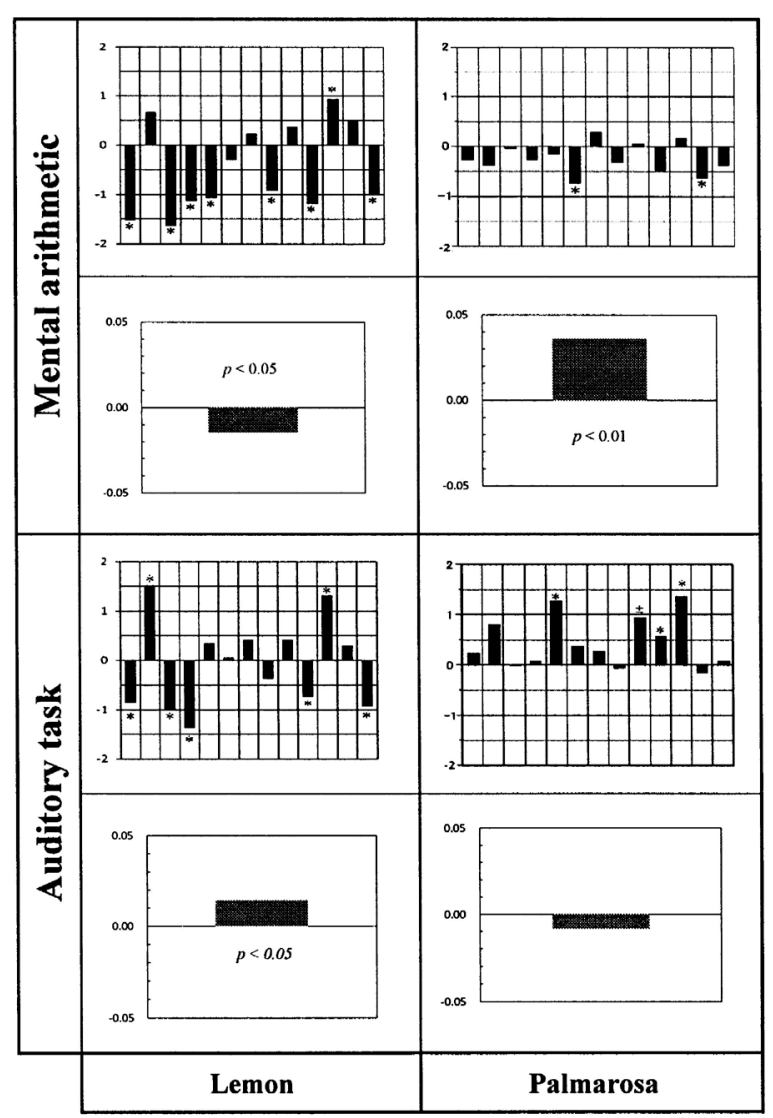

(a)

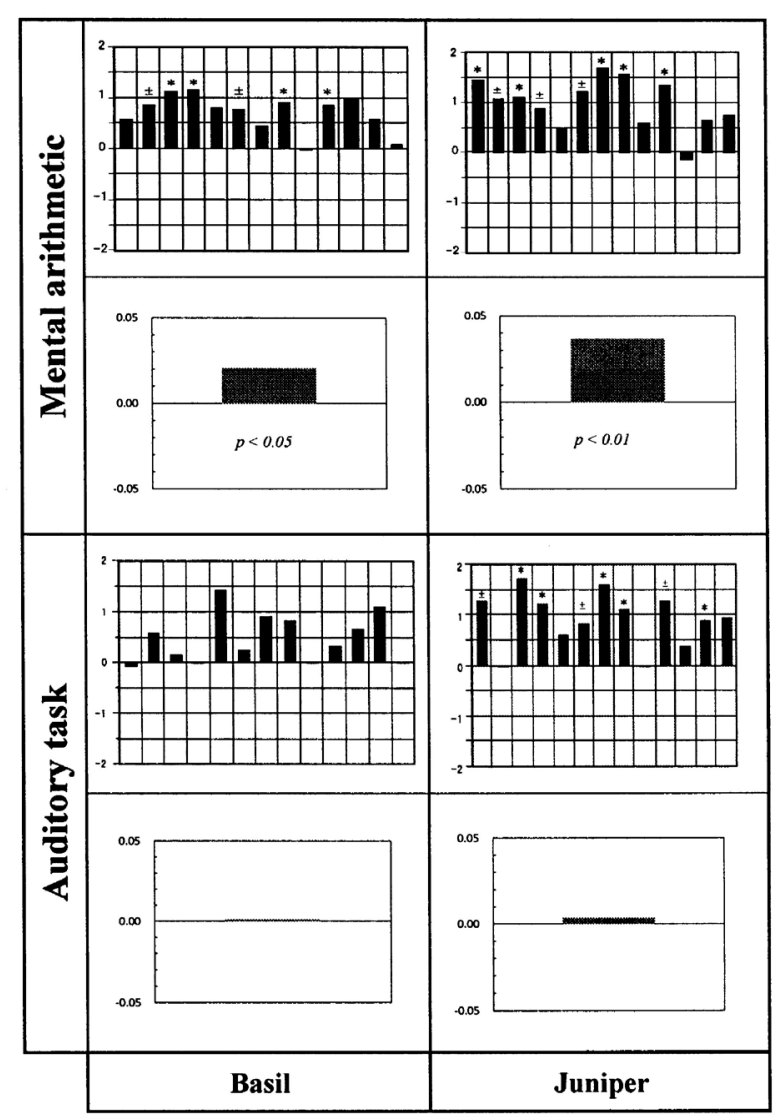

(b)

Figure 6. Summary of the verbal and non-verbal responses following inhalation of essential oils of lemon, palmarosa, basil, and juniper. Figure shows sensory evaluation spectra and skin temperature changes as a function of two behavioral tasks. (a) lemon and palmarosa; and (b) basil and juniper. See Table 1 and the text for more information about the participants in the sensory profiling study and the skin temperature study, respectively.

cinnamon, orange, peppermint, sandalwood, spearmint, and ylangylang, which elicited a decrease in skin temperature regardless of the behavioral task assigned to the participants.

Lemon and palmarosa, which we assigned to the first category in our criteria, produced task-dependent responses. As previously mentioned, lemon produced opposing effects for the two behavioral tasks: a significant decrease in skin temperature between pre- and post-task inhalations for mental arithmetic (at $p<0.05$ ), and a significant increase in skin temperature for the auditory task (at $p<0.05$ ). Palmarosa elicited similar task-dependent characteristics to lemon in terms of fingertip skin temperature. Essential oils of basil and juniper, which we assigned to the second category, elicited increases in skin temperature as well as an increase in the sensory spectra for the two tasks, both in a non-task dependent fashion. Contrary to this, essential oils of bergamot, cardamom, cinnamon, orange, peppermint, sandalwood, spearmint, and ylangylang, which were placed in the third category, decreased skin temperature for the two tasks in a non-task dependent fashion. However, the latter half of the group (bergamot, peppermint, sandalwood, and ylangylang) were associated with contrasting directions of change in the sensory spectra for the two tasks.

With respect to the essential oils belonging to the third category in our criteria (bergamot, cardamom, cinnamon, orange, peppermint, sandalwood, spearmint, and ylangylang), a more detailed inspection of the obtained sensory spectrographs led us to classify these further into two groups: those associated with contrasting sensory spectra in a task-dependent fashion (i.e., one produced an increase and the other produced a decrease); and those (the rest) associated with undistinguished sensory spectra. Essential oils of bergamot, peppermint, sandalwood, and ylangylang appeared to the former, whereas cardamom, cinnamon, orange, and spearmint constituted the latter. 

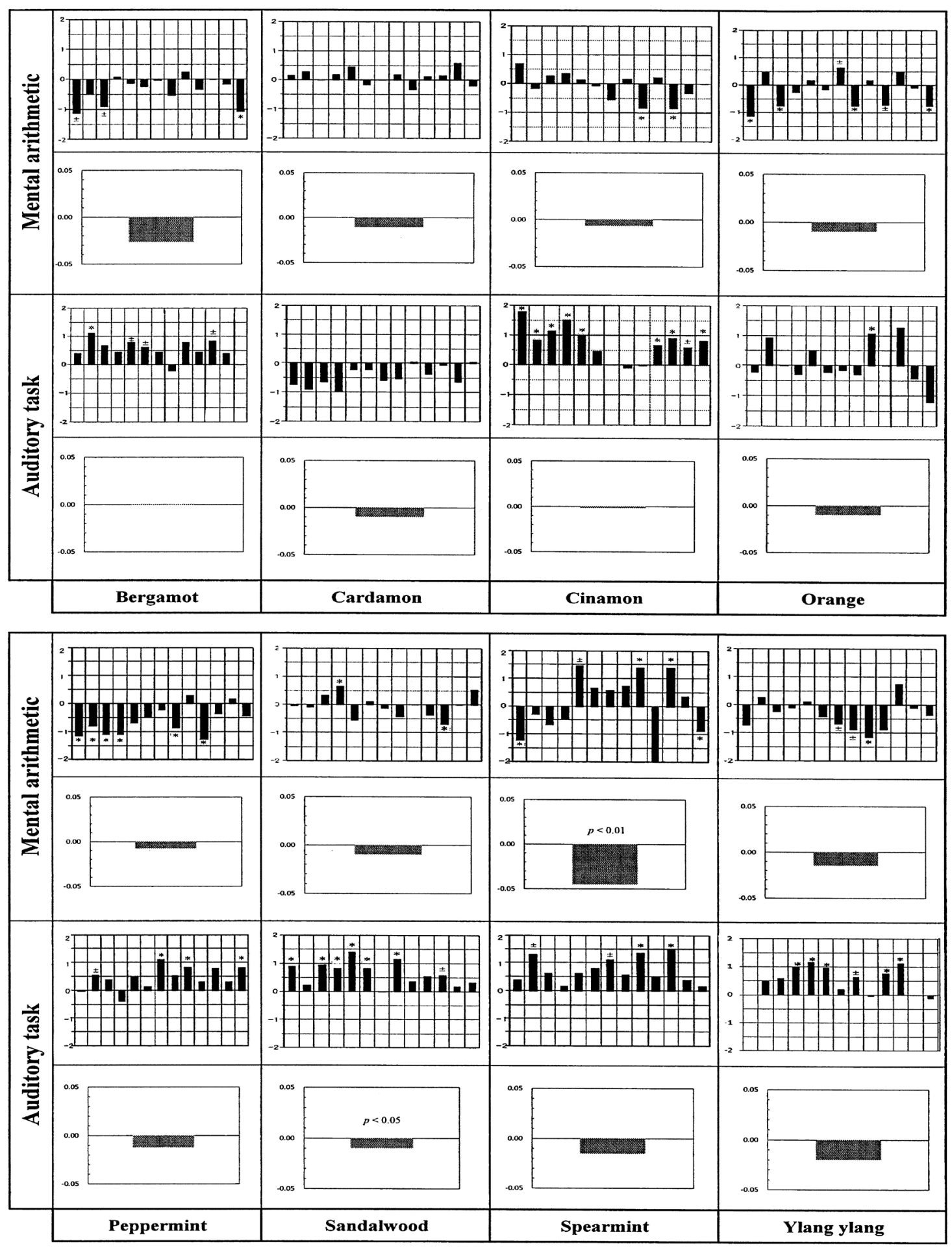

Figure 7. Summary of the verbal and non-verbal responses following inhalation of bergamot, cardamom, cinnamon, orange, peppermint, sandalwood, spearmint, and ylangylang essential oils in terms of the sensory evaluation spectra and skin temperature changes as a function of two behavioral tasks. The circumstances are identical to those shown in Figure 6.

In our research, the verbal tests always antedated the non-verbal tests because the verbal tests were used to screen the essential oils that would be used in the non-verbal investigations. As for information about the number 
of the participants in the former antedated verbal tests, see Table 1. As to the number of participants in the latter non-verbal tests who completed the mental arithmetic task while we conducted skin temperature measurements was 17 for basil, 14 for bergamot, 18 for cardamom, 18 for cinnamon, 12 for juniper, 13 for lemon, 20 for orange, 11 for palmarosa, 18 for peppermint, 20 for sandalwood, 17 for spearmint, and 18 for ylangylang. The number of participants who completed the auditory task while we conducted skin temperature measurements was 19 for basil, 12 for bergamot, 20 for cardamom, 18 for cinnamon, 20 for juniper, 14 for lemon, 20 for orange, 18 for palmarosa, 20 for peppermint, 20 for sandalwood, 18 for spearmint, and 20 for ylangylang.

\section{Discussion}

Sensory analysis can involve a variety of tools and tests for participative or objective evaluation of sensory properties. Among these, descriptive sensory analysis employs a group of trained individuals (generally 6 - 12) who identify and quantify specific sensory attributes (Drake, 2004, 2007; Lawless \& Heymann, 1988; Meilgaard et al., 1999). In contrast, our sensory analysis involved untrained individuals as panelists, resulting in variations in the level of interest in the sensory target, sensitivity to the stimuli, and susceptibility to fatigue. As described elsewhere (Sugawara, 2008; Sugawara et al., 2009a; Yamagata \& Sugawara, 2014), this was evident from our questionnaire, whereby the standard deviation of the responses was remarkably large when compared with the value of the mean for the 13 descriptors studied. Considering the large standard deviation, these means were statistically non-significant.

Regardless, sensory spectra can represent specific sensory attributes at a level of quality that is equal to that of the traditional (conventional) descriptive sensory analyses (Sugawara, 2008; Sugawara et al., 2009a, 2013; Yamagata \& Sugawara, 2014). While the traditional analysis involves groups of trained individuals who identify and quantify specific sensory attributes with the goal of reproducibility and consistency, we believe that our obtained sensory spectra exhibited satisfactory-to-good agreement both in terms of reproducibility and consistency, as well as the shape and characteristics of the total significance scores (i.e., the sum of the statistical scores for each descriptor in a given sensory evaluation spectrum: 1.0 for items denoted with *; 0.5 for items denoted with \pm ; 0.0 for items that are unmarked). Additionally, we substantiated the number of panelists required for our study, and showed that this number was similar to that required in conventional descriptive sensory analysis, even if using untrained (inexperienced) individuals on the panel.

In this context, we employed sensory spectra as a measure (sensory profiling) of the perceived odor quality in participants after inhalation of a given aroma on the basis of the task-dependent sensory questionnaire assessments in this research.

There are roughly two types of sensory spectra. The first type includes descriptors regarded as significant by a $t$-test with a positive value; these were shown above the horizontal axis. The other type includes descriptors that had negative values; these appeared below the horizontal axis. The former spectra denote positive (or favorable) correlation between the fragrance of a given aroma and the type of task using descriptors like "fresh," "airy," "elegant," "pleasant," “comfortable," among others, while the latter spectrographs suggest an unfavorable (negative) correlation between the fragrance and the type of task in terms of the setting descriptors.

The spectra derived from lemon/mental arithmetic (Figure 1(a)) and ylangylang/mental arithmetic (Figure 1(b)) as well as linalool/mental arithmetic (Figure 1(c)) seemed to be examples showing unfavorable (negative) correlation between the fragrance and the type of task assigned to the participants. On the other hand, the spectra resulting from ylangylang/auditory task (Figure 1(e)) and linalool/auditory task (Figure 1(f)) were seen in favorable (positive) type. Besides, there was a type of spectrograph like lemon/auditory task (Figure 1(d)), wherein half of the significant descriptors were positive and the other half negative. Peculiarly, ylangylang produced opposite signs for the two behavioral tasks in terms of sensory spectrograph: an unfavorable (negative) type in association with the mental arithmetic task (Figure 1(b)) and a favorable (positive) type in relation to the auditory task (Figure 1(e)). Similar task-dependent results were found in inhaling the fragrances of essential oils of bergamot, peppermint and sandalwood (Figure 7) as well as linalool (Figure 1(c) and Figure 1(f)).

Equally, $(R)-(-)-$ linalool in association with the auditory task was found to produce positive (favorable) values in the sensory spectrum (Figure 3(e)), and this effect was quite similar to that of $(R S)-( \pm)$-linalool (Figure 3(d)) but contrasted with that of $(S)-(+)$-linalool (Figure 3(f)). In contrast, $(R)-(-)$-linalool in association with mental arithmetic (Figure 3(b)) produced negative (unfavourable)values in the spectrum (that is, perceived odour quality), and this feature closely resembled the effects of $(S)-(+)$-linalool (Figure 3(c)) and (RS)-( \pm )-linalool (Figure 3(a)). Taken together with the previous report that the aromas of $(+)$ - and (-)-linalool are petitgrain-like 
and lavender-like, respectively (Ohloff \& Klein, 1962), our findings suggest that the enantiomers of linalool are significantly different odorants and also that the perception of them is task-dependent.

Thus, the resulting sensory spectra (Figure 1 and Figure 3) warranted particular interest. However, the changes of the spectra listed in Table 1 including the cases in Figure 1 and Figure 3 were insignificant. Because we did not find any sensory spectra with a total significance score of $>10$ among our 50-case studies. We expect that this is due to extraordinary deviation in both the pre- and post-task descriptor scores (Sugawara, 2008; Sugawara et al., 2009a; Yamagata \& Sugawara, 2014).

Along with the line of this thinking, we considered a variety of strategies for addressing statistical defects associated with the significance of the sensory spectra. As we have mentioned, we conclusively found that multichannel skin thermometer data might complement the statistical defects of the relevant sensory spectra. The diagrams shown in Figure 6 demonstrate that the practical potentialities of the skin temperature data for the evaluation of statistical significance might complement any statistical defects associated with the sensory spectrographs, even if the sensory spectra were not statistically significant. Moreover, the subtle differences between the two behavioral tasks could be viewed in terms of verbal (sensory spectrum) and non-verbal (fingertip skin temperature) expressions as a function of the two behavioral tasks.

Throughout the fingertip skin temperature measurements, we concentrated our focus to involve only the following 12 essential oils (basil, bergamot, cardamom, cinnamon, juniper, lemon, orange, palmarosa, peppermint, sandalwood, spearmint and ylangylang). Based on the relationship between verbal and non-verbal responses of the 12 target odors during the two tasks (mental arithmetic and the auditory), we tentatively classified our 24 odor-task combinations into three categories: (1) the first category (Figure 6(a)) included lemon and palmarosa because they elicited opposite changes in skin temperature for the two behavioral tasks; (2) the second category (Figure 6(b)) contained basil and juniper, as these were associated with increases in skin temperature for the two behavioral tasks in a non-task dependent fashion; and (3) the other essential oils were placed in the third category (Figure 7), since inhalation of these essential oils was associated with decreases in skin temperature for the two tasks in a non-task dependent fashion.

Moreover, it was apparent that the 24 odor-task combinations could be divided into two groups in terms of skin temperature changes between pre- and post-task inhalations: those that elicited an increase (Figure 6(b)); and those that led to a decrease (Figure 7). Emotional excitement or apprehension is known to induce a slight increase in human skin temperature (Elam \& Wallin, 1987; Oka et al., 2001, 2008; Yamakoshi et al., 2007; Ziegler \& Cash, 1938), although the mechanisms by which odorants induce such changes are unknown, and what's more the complicated factors influence cutaneous vascular responses with respect to skin temperature changes (Abramson \& Ferris 1940; Allwood et al., 1959; Arnott \& Macfie, 1948; Elam \& Wallin, 1987; Harris et al., 1952; Gaskell, 1956; Kellerova \& Delius 1969; Roddie, 1983; Roddie et al. 1957; Rowell, 1981; Vallbo et al., 1979). However, if feelings of excitement or apprehension induce slight increases in skin temperature (Elam \& Wallin, 1987; Oka et al., 2001, 2008; Yamakoshi et al., 2007; Ziegler \& Cash, 1938), it is reasonable to assume that our target odors can be regarded as having either distressing/agitating sentiments when associated with increases in skin temperature (Figure 6(b)) or relaxing/sedating sentiments when associated with decreases in skin temperature (Figure 7).

Mehrabian and Russell (1974) constructed a set of verbal texts describing different situations, and a scale for rating these texts (the Semantic Differential Scale). They asserted that pleasure and arousal are the principal dimensions of affective response to the environment. Here, pleasure can be defined as the degree to which one has favorable feelings towards a situation, while arousal is defined as the degree to which one feels excited in the situation. When this method was applied to materials describing common events, Bensafi et al. (2002) demonstrated that the first two factors accounting for most of the variance in descriptions were pleasure and arousal. Perception of emotional stimuli is thus associated with explicit reactions, such as verbal responses, and to implicit output, such as variations in the autonomic nervous system (Greenwald et al., 1989; Lang et al., 1998).

Based on Bensafi et al. (2002) we speculated that: (1) the sensory spectra can be used as an index of pleasantness (or unpleasantness); and (2) the overall mean values of the net skin temperature changes between preand post-task inhalations can be regarded as an index of arousal state. Specifically, upward sensory spectra can be considered to represent favorable (pleasant) feelings towards a situation while participants inhale the fragrance of a given aroma, whereas downward sensory spectra can represent unfavorable (unpleasant) feelings towards a situation. Likewise, an increase in skin temperature (i.e., the overall mean values of the net skin temperature changes between pre- and post-task inhalations) could designate a distressed/agitated state of the par- 
ticipant as well as distressing/agitating properties of a given aroma, while a decrease could denote a relaxed/sedated state and relaxing/sedating properties of a target odor.

Along this line of thinking, it seemed that administration of basil and juniper, which were members of the second category in our criteria (Figure 6(b)), could bring about favorable/pleasant feelings in terms of non-task dependent upward sensory spectra and lead distressing/agitating sentiments associated with non-task dependent increases in skin temperature. In this context, however, group membership of bergamot, cardamom, cinnamon, orange, peppermint, sandalwood, spearmint, and ylangylang as these being assigned to the third category in our criteria (Figure 7) would be confusing. This is why the essential oils belonging to the third category in our criteria could be divided into two groups: those (bergamot, peppermint, sandalwood, and ylangylang) associated with contrasting sensory spectra in a task-dependent fashion (one was upward and the other was downward); and the remainder (cardamom, cinnamon, orange, and spearmint) that were associated with contrasting sensory spectra in a non-task-dependent fashion.

Here we will address the former group of essential oils first, i.e., those comprising exactly half of the essential oils in our third category. This is because Hongratanaworakit and Buchbauer made an intriguing observation during two studies of ylangylang in 2004 and 2006. Hence, we will hereinafter deal with ylangylang as a typical example of this group, for which a characteristic feature could be an obtained sensory spectra that clashes with the results of behavioral tasks in terms of direction: the sensory spectrograph was upward when the participants completed the mental arithmetic task and downward when they completed the auditory task. Note that the decreases in skin temperature associated with the two tasks were identical to those found for the remaining essential oils (cardamom, cinnamon, orange, and spearmint).

In Hongratanaworakit and Buchbauer's first study (2004), the authors characterized the effect of ylangylang after inhalation as harmonizing rather than relaxing/sedating on the basis of their findings that administration of ylangylang after inhalation led to a decrease in blood pressure and pulse rate. However, they observed increased participative attention and alertness in response to administration of ylangylang. Thus, they generated the concept of "harmonization," which is consistent with otherwise contradictory psychophysiological outcomes. In their subsequent report (Hongratanaworakit \& Buchbauer, 2006), the authors reported that transdermal absorption of ylangylang caused a decrease in blood pressure and an increase in participative calmness and relaxation compared with a control scenario, and suggested that administration of ylangylang via transdermal absorption has a relaxing/sedating effect under specific experimental conditions.

Given their findings, our ylangylang data is intriguing. The inhalation of ylangylang in combination with mental arithmetic produced an unpleasant/unfavorable feeling after inhalation, whereas inhalation combined with the auditory task brought about a pleasant (favorable) feeling. Conversely, ylangylang seemed to have similar relaxing/sedating properties during both the mental arithmetic and the auditory tasks. It seems that the observed effect of ylangylang in our experiment, in combination with mental arithmetic, was in good agreement with the Hongratanaworakit and Buchbauer's conception of "harmonization" (2004). Given this notion, we searched for other essential oils that had the same profile as ylangylang in terms of task-dependent sensory spectra and fingertip skin temperature changes. The results are shown in Figure 8(a). We identified three other essential oils that shared the sensory spectra of ylangylang in terms of net intensity fingertip skin temperature changes. These were bergamot, peppermint, and sandalwood.

Thus, we reconsidered the remaining half of the essential oils (cardamom, cinnamon, orange, and spearmint) in our third category, as shown in Figure 8(b). They all were associated with decreases in skin temperature during the two behavioral tasks, but we found no common features in their sensory spectra. The total significance scores for these essential oils were mostly less than 3 , so we expected that a null hypothesis could be rejected. A small exception was seen for a cinnamon/auditory task (a total significance score of 8.5) and a spearmint/mental arithmetic (a total significance score of 4.5). Additionally, in the sensory spectrograph for spearmint/mental arithmetic, half of the significant descriptors were positive and the other half negative. Altogether, the essential oils belonging to this group (cardamom, cinnamon, orange, and spearmint) could be regarded as having relaxing/sedating properties, as shown in Figure 8(b).

Lemon and palmarosa were classified as miscellaneous, as these were assigned to the first category in our criteria (Figure 6(a)) on the basis that inhalation of lemon and palmarosa produced skin temperature responses in opposite directions for the two behavioral tasks. Based on the above discussion, that a significant increase in skin temperature was elicited by lemon/the auditory task (at $p<0.05$ ) and palmarosa/mental arithmetic (at $p<$ 0.01 ) could indicate that these essential oils have distressing/agitating properties. However, a significant 


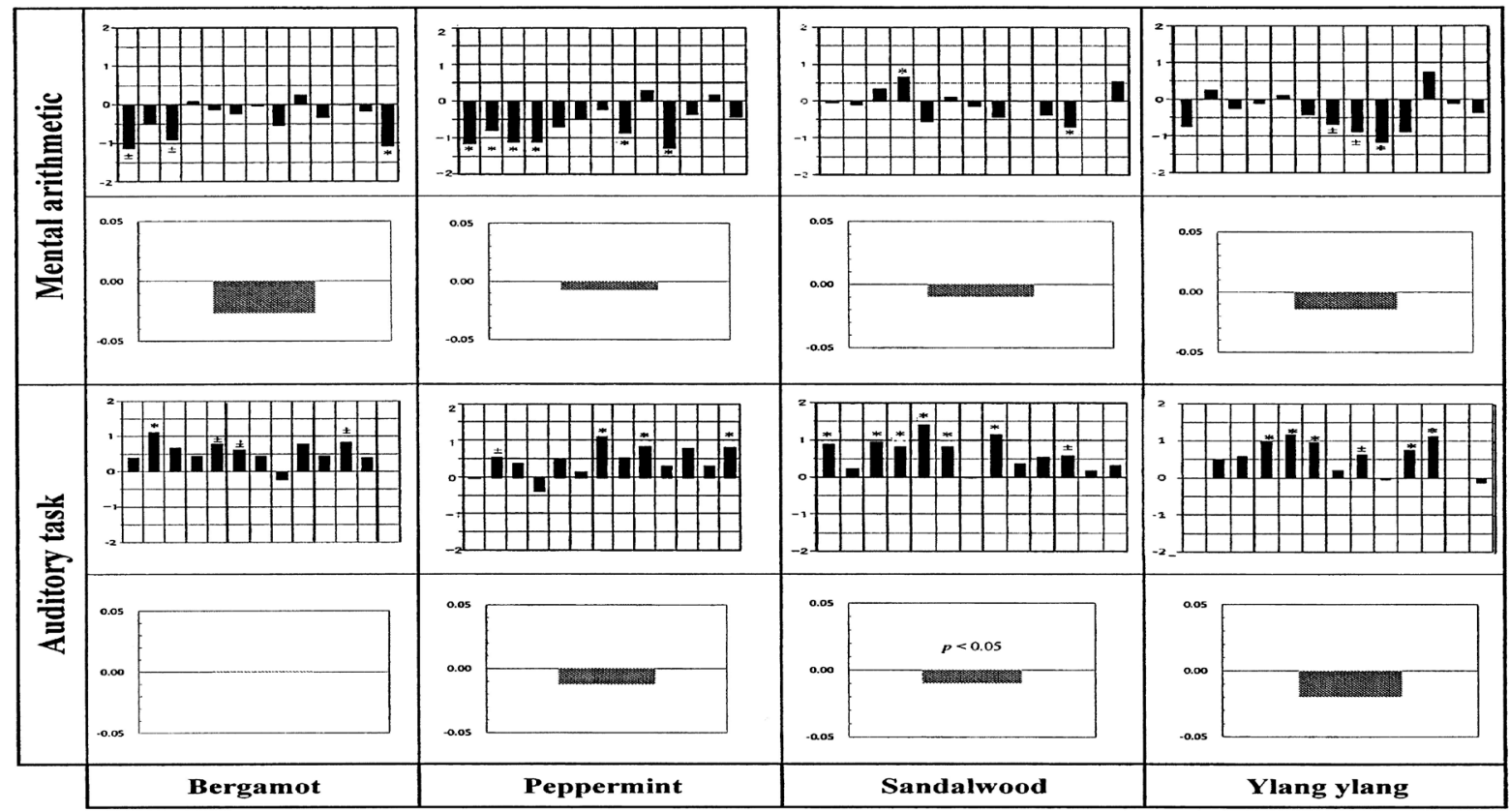

(a)

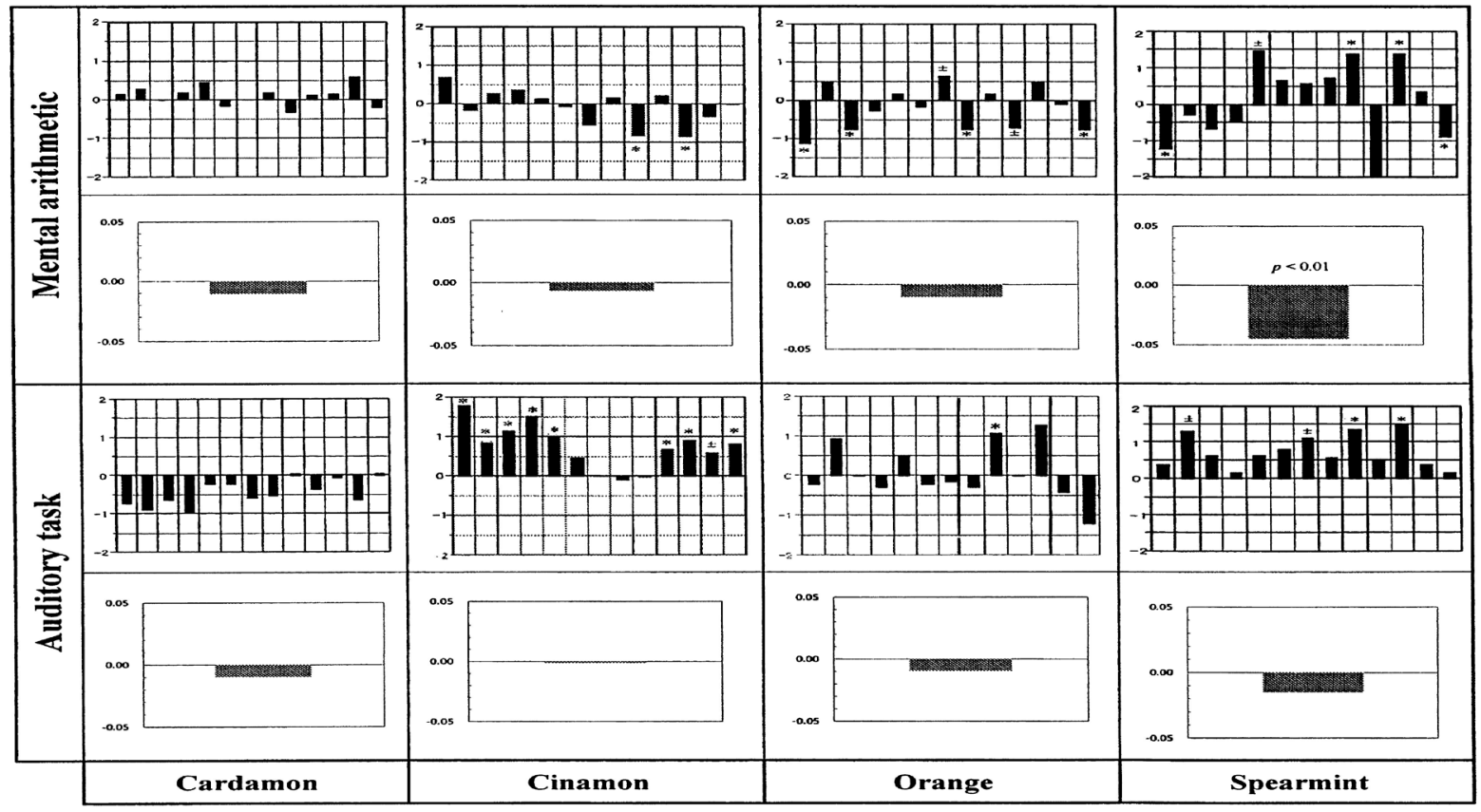

(b)

Figure 8. Reconstruction of the architecture of Figure 7, employing the concept of "harmonization” introduced by Hongratanaworakit and Buchbauer to describe the effect of ylangylang (2004). In terms of the sensory spectra and skin temperature changes as a function of two behavioral tasks assigned to the participants, (a) includes essential oils showing "harmonization"; and (b) shows those without "harmonization".

decrease in skin temperature induced by lemon/mental arithmetic (at $p<0.05$ ) and palmarosa/the auditory task (although this change did not reach statistical significance) could be regarded as a reflection of their relaxation/sedation properties.

Controversial findings are often reported in aroma research. It is of particular importance to mention the 
controversy surrounding the lemon fragrance. Support for the hypothesis that the lemon fragrance causes distress/agitation has been provided by the observation that lemon aroma causes an increase in heart rate (Kikuchi et al., 1992; Yamaguchi, 1990). However, the opposite is supported by the findings of a study by Manley (1993), in which the administration of a lemon aroma through an air conditioning system resulted in a decrease in contingent negative variation (CNV) as well as a decrease in key entry errors of video display terminal (VDT) operators. In a recent study (Akipinar, 2005) in which the author was interested in identifying the effects of lemon on cognitive learning, attention, and memory, a lemon aroma increased the attention levels of students (at $p<0.05)$, enhanced memory (at $p<0.05$ ), and had positive effects on cognitive learning (at $p<0.05$ ).

Similar controversies exist for other aromas. For instance, Manley (1993) reported that a ylangylang aroma appeared to possess a stimulating effect, as it caused an increase in CNV magnitude. Hongratanaworakit and Buchbauer $(2004,2006)$ demonstrated that its effect can be characterized as relaxation/sedation. With respect to sandalwood, Hongratanaworakit, Heuberger, and Buchbauer compared the effects of sandalwood administered via transdermal absorption (Hongratanaworakit et al., 2004) and inhalation (Heuberger et al., 2006) on physiological parameters, as well as mental and emotional conditions, in healthy human participants. The authors concluded that the administration of sandalwoodoil via transdermal absorption and in specific experimental conditions provoked physiological deactivation and behavioral activation (Hongratanaworakit et al., 2004), while administration via inhalation and in different experimental circumstances elevated pulse rate, skin conductance level, and systolic blood pressure (Heuberger et al., 2006). As for peppermint, evidence for its stimulating properties includes an observation that peppermint aroma caused an increase in electroencephalography (EEG) speed and heart rate during sleep (Badia et al., 1990), an increase in CNV magnitude (Manley, 1993, Torii et al., 1988), a decrease in theta activity (Klemm et al., 1992), and enhanced EEG and behavioral arousal during stage 1 sleep (Carskadon \& Herz, 2004). However, arguments against the stimulating properties of peppermint include the finding that peppermint aroma produced a significant decrease in gross speed, net speed, and accuracy in a typing task (Barker et al., 2003); more NREM sleep, less REM sleep, and more slow-wave sleep (Goel \& Lao, 2006); and increased alertness, decreased temporal demand, and decreased frustration during simulated driving (Raudenbush et al., 2009).

In consideration of the above-mentioned opposing views about the psychophysiological properties of essential oils, and given our findings regarding the subtle nuances of expression between the verbal (psychological) and non-verbal (physiological) effects of essential oil aromas in humans, the described controversies may in part be a reflection of the versatile psychophysiological properties of essential oils. Specifically, essential oils seem to function as neurophysiological stimuli that can cause different perceptions and elicit diverse reactions, depending on the internal and extraneous conditions of the participants, as well as manifestations of higher-order olfactory processing.

The unique features related to early levels of the olfactory system have been extensively studied and documented (Axel, 1995; Buck, 1996; Buck \& Axel, 1991; Li et al., 2008; Lledo et al., 2005; Mombaerts, 1999; Yoshida \& Mori, 2007; Zhang \& Firestein, 2002), however, little is known about processes operating upstream. Further research is needed to characterize the mechanisms underlying odor discrimination beyond the early stages of olfactory processing. The limbic system is likely to be involved, as it includes the amygdala, septum, hippocampus, anterior thalamus, and hypothalamus. It plays a vital role in motivation, memory, emotions, and instinctive behaviors (Buckle, 2004; Price \& Price, 2007). Thus, it is possible that the elucidation of higher-order olfactory processing, as well as an improved understanding of the versatile psychophysiological properties of essential oils, especially those associated with task-dependence, may contribute to the resolution of several controversies often seen in aroma research. To address these issues, further studies of these phenomena should consider external conditions, such as behavioral tasks assigned to participants. Such studies will potentially contribute to aroma research and the study of human chemoreception, enabling a deeper understanding of the working principles of the highly sophisticated human olfactory system.

\section{Conclusion}

1) We have attempted to examine the relationship between mood change, odor and its psychophysiological responses, by focusing on the possible verbal (semantic) and non-verbal (skin temperature) changes in humans induced by smelling the fragrances of essential oils as well as linalool and its enantiomers. The obtained findings suggest that our verbal inspections together with non-verbal tests are useful for shedding more light on the finer nuances of odor discrimination and psychophysiological responses to odorants in humans. 
2) This article is an overview of our verbal (semantic) research results as well as the non-verbal outcomes over the past decade. Because we believe that this approach has the potential to be highly informative, so that such information may provide clues to our long-standing issue how precisely humans and their olfactory system can detect and discriminate a great variety of odors and subtle differences in the molecular structures of a given aroma.

3) Sensory evaluation has been a key component in a series of our research activities. In our semantic inquiry, we asked the participants to complete behavioural tasks during fragrance exposure. We used the Uchida-Kraepelin test as a mental arithmetic task and listening to environmental (natural) sounds as an auditory task. The sensory test was conducted twice, once before and once after the task. We then represented the perceived sensory attributes reported by the participants via a bar graph (sensory spectrograph), whereby the mean of the impressions was plotted against the semantic descriptors.

4) Specifically, in the case of ylangylang spectrum in association with mental arithmetic, there was an unfavorable (or negative) correlation between the fragrance and the type of task assigned to the subject. On the other hand, ylangylang spectrum in relation to the auditory task was shown to be positive correlation between the fragrance and the task. Similar results were found for bergamot, peppermint and sandalwood essential oils as well as linalool. This implies that different behavioural tasks influence the perceived odor quality of inhaling odorants. Moreover, the finer nuances visible in the appearance of each spectrum show how this method of sensory profiling can be practical for assessing odor perception in participants.

$5)$ Equally, inhalation of $(R)-(-)$-linalool or $(R S)-( \pm)$-linalool in association with the auditory task produced a positive impression of odour quality, whereas this effect was not seen for $(S)-(+)$-linalool. In contrast, administration of $(R)-(-)$-linalool, $(S)-(+)$-linalool and $(R S)-( \pm)$-linalool in association with mental arithmetic all produced a negative impression of odour quality. This indicates that the enantiomers of linalool have different smells and that the perception of them is task-dependent.

6) The resulting sensory spectra warranted particular interest. However, there were no sensory spectra wherein the changes of the spectra were significant among the 50 cases including the 21 essential oils and linalool as well as its enantiomers as a function of the two behavioral tasks (mental arithmetic task and the auditory task).

7) Hence, we considered a variety of strategies for addressing statistical defects associated with the significance of the sensory spectra. Conclusively, we found that multi-channel skin thermometer data might complement the statistical defects of the relevant sensory spectra. That is, the practical potentialities of the skin temperature data for the evaluation of statistical significance might complement any statistical defects associated with the sensory spectrographs, even if the sensory spectra were not statistically significant.

8) Throughout the skin temperature measurements, we concentrated our focus to involve only the following 12 essential oils (basil, bergamot, cardamom, cinnamon, juniper, lemon, orange, palmarosa, peppermint, sandalwood, spearmint and ylangylang).

9) Based on the relationship between verbal and non-verbal responses of the 12 target odors during the two tasks (mental arithmetic and the auditory), we classified the 24 odor-task combinations into three categories: 1) the first category, which included lemon and palmarosa, elicited task-dependent dual changes in fingertip skin temperature; 2) the second category, which included basil and juniper, not only elicited an increase in skin temperature, but also the increased sensory spectra in a non-task dependent fashion; and 3) the third category, which included bergamot, cardamom, cinnamon, orange, peppermint, sandalwood, spearmint, and ylangylang, which elicited a decrease in skin temperature regardless of the behavioral task assigned to the participants.

10) Thus, the subtle differences between the two behavioral tasks while inhaling the fragrances of the abovementioned 12 target odors could be viewed in terms of verbal (sensory spectrum) and non-verbal (fingertip skin temperature) expressions as a function of the two behavioral tasks.

11) If feelings of excitement or apprehension induce slight increases in skin temperature, it is reasonable to assume that our target odors can be regarded as having either distressing/agitating sentiments when associated with increases in skin temperature or relaxing/sedating sentiments when associated with decreases in skin temperature. YlangYlang could be such a representative example. Decreases in skin temperature measurements while inhaling the fragrance of ylangylang indicated that inhalation of ylangylang brought about relaxing/sedating sentiments in the participants for both the mental arithmetic and auditory tasks. In contrast, the sensory spectra showed that an unfavorable impression of the odor was associated with mental arithmetic, whereas a favorable impression was associated with the auditory task.

12) Our results of ylangylang were in good agreementwith the conception of "harmonizing" rather than relaxing/sedating, which was introduced by Hongratanaworakit and Buchbauer (2004) to describe the psychophy- 
siological effects of ylangylang inhalation. When we used the obtained sensory spectra and skin temperature profiles of ylangylang as a reference to evaluate the other tested odorants, we found that bergamot, peppermint and sandalwood could be classified as "harmonizing".

13) Odorant receptors are encoded by the largest gene family thus far identified, making it a very diverse group of receptors. In our studies, however, the fragrance administered to the participants was well controlled and should activate the same set of receptors regardless of behavioral task.

14) Hence, the observed task-dependence of odorperception and psychophysiological responses likely originates from higher-order processes in the brain. A great deal is known about the initial stages of olfactory processing, but much less is known about processes beyond the olfactory bulb. Our research over the past decade indicates that further work is needed to characterize the mechanisms of odour discrimination beyond the nasal epithelium.

\section{References}

Abramson, D. L., \& Ferris, E. B. (1940). Responses of Blood-Vessels in the Resting Hand and Forearm to Various Stimuli. American Heart Journal, 19, 541-553. http://dx.doi.org/10.1016/S0002-8703(40)90195-8

Akipinar, B. (2005). The Role of Sense of Smell in Learning and the Effects of Aroma in Cognitive Learning. Pakistan Journal of Social Sciences, 3, 952-960.

Allwood, M. J., Barcroft, H., Hayes, J. P. L. A., \& Hirsjarvi, E. A. (1959). The Effect of Mental Arithmetic on the Blood Flow through Normal, Sympathectomized and Hyperhidrotic Hands. The Journal of Physiology, 148, 108-116. http://dx.doi.org/10.1113/jphysiol.1959.sp006276

Arnott, W. M., \& Macfie, J. M. (1948). Effect of Ulnar Nerve Block on Blood Flow in the Reflexly Vasodilated Digit. The Journal of Physiology, 107, 233-238.

Axel, R. (1995). The Molecular Logic of Smell. Scientific American, 273, 130-137. http://dx.doi.org/10.1038/scientificamerican1095-154

Badia, P., Wesensten, N., Lammers, W., Culpepper, J., \& Harsh, J. (1990). Responsiveness to Olfactory Stimuli Presented in Sleep. Physiology Behavior, 48, 87-90.

Barker, S., Grayhem, R, Koon, J., Perkins, J., Whalen, A., \& Raudenbush, B. (2003). Improved Performance on Clerical Tasks Associated with Administration of Peppermint Odor. Perceptual Motor Skills, 97, 1007-1010.

http://dx.doi.org/10.2466/pms.2003.97.3.1007

Bensafi, M., Rouby, C., Farget, V., Bertrans, B., Vigouroux, M., \& Holley, A. (2002). Autonomic Nervous System Responses to Odours: The Role of Pleasantness and Arousal. Chemical Senses, 27, 703-709. http://dx.doi.org/10.1093/chemse/27.8.703

Billot, M., \& Wells, F. (1975). Perfumery Technology: Art, Science, Industry. New York: John Wiley.

Buchbauer, G., \& Jirovetz, L. (1994). Aromatherapy-Use of Fragrances and Essential Oils as Medicaments. Flavour and Fragrance Journal, 9, 217-222. http://dx.doi.org/10.1002/ffj.2730090503

Buck, L. (1996). Information Coding in the Vertebrate Olfactory System. Annual Review of Neuroscience, 19, 517-544. http://dx.doi.org/10.1146/annurev.ne.19.030196.002505

Buck, L., \& Axel, R. (1991). A Novel Multigene Family May Encode Odorant Receptors: A Molecular Basis for Odor Recognition. Cell, 65, 175-187. http://dx.doi.org/10.1016/0092-8674(91)90418-X

Buckle, J. (1999). Use of Aromatherapy as a Complementary Treatment for Chronic Pain. Alternative Therapies in Health and Medicine, 5, 42-51.

Buckle, J. (2004). Clinical Aromatherapy: Essential Oils in Practice (2nd ed.). New York: Elsevier.

Carskadon, M. A., \& Herz, R. S. (2004). Minimal Olfactory Perception during Sleep: Why Odor Alarms Will Not Work for Humans. Sleep, 27, 402-405.

Coombs, C. H. (1964). Theory of Data. New York: John Wiley.

Drake, M. A. (2004). Defining Dairy Flavors. Journal of Dairy Science, 87, 777-784. http://dx.doi.org/10.3168/jds.S0022-0302(04)73221-X

Drake, M. A. (2007). Sensory Analysis of Dairy Foods. Journal of Dairy Science, 90, 4925-4937. http://dx.doi.org/10.3168/jds.2007-0332

Edge, J. (2003). A Pilot Study Addressing the Effect of Aromatherapy Massage on Mood, Anxiety and Relaxation in Adult Mental Health. Complementary Therapies in Nursing and Midwifery, 9, 90-97. http://dx.doi.org/10.1016/S1353-6117(02)00104-X

Elam, M., \& Wallin, B. G. (1987). Skin Blood Flow Responses to Mental Stress in Man Depend on Body Temperature. Acta 
Physiologica Scandinavica, 129, 429-431. http://dx.doi.org/10.1111/j.1365-201X.1987.tb10609.x

Firestein, S. (1991). A Noseful of Odor Receptors. Trends in Neurosciences, 14, 270-272. http://dx.doi.org/10.1016/0166-2236(91)90135-H

Friedman, L., \& Miller, J. G. (1971). Odor Incongruity and Chirality. Science, 172, 1044-1046. http://dx.doi.org/10.1126/science.172.3987.1044

Gaskell, P. (1956). Are There Sympathetic Vasodilator Nerves to the Vessels of the Hand? The Journal of Physiology, 131, 647-656. http://dx.doi.org/10.1113/jphysiol.1956.sp005489

Goel, N., \& Lao, R. P. (2006). Sleep Changes Vary Odor Perception in Young Adults. Biological Psychology, 71, $341-349$. http://dx.doi.org/10.1016/j.biopsycho.2005.07.004

Greenwald, M. K., Cook, E. W., \& Lang, P. J. (1989). Affective Judgment and Psychophysiological Response: Dimensional Covariation in the Evaluation of Pictorial Stimuli. Journal of Psychophysiology, 3, 51-64.

Guilford, J. P. (1954). Psychometric Methods. New York: McGraw-Hill.

Harris, R., Martin, A. J., \& Williams, H. S. (1952). Correlation of Skin Temperature and Circulatory Changes in Muscle and Subcutaneous Tissues of the Hand during Trunk Heating. Clinical Science, 11, 429-440.

Heuberger, E., Hongratanaworakit, T., \& Buchbauer, G. (2006). East Indian Sandalwood and $\alpha$-Santalol Odor Increase Physiological and Self-Rated Arousal in Humans. Planta Medica, 72, 792-800. http://dx.doi.org/10.1055/s-2006-941544

Holmes, C., Hopkins, V., Hensford, C., MacLaughlin, V., Wilkinson, D., \& Rosenvinge, H. (2002). Lavender Oil as a Treatment for Agitated Behaviour in Severe Dementia: A Placebo Controlled Study. International Journal of Geriatric Psychiatry, 17, 305-308. http://dx.doi.org/10.1002/gps.593

Hongratanaworakit, T., Heuberger, E., \& Buchbauer, G. (2004). Evaluation of the Effects of East Indian Sandalwood Oil and $\alpha$-Santalol on Humans after Transdermal Absorption. Planta Medica, 70, 3-7. http://dx.doi.org/10.1055/s-2004-815446

Hongratanaworakit, T., \& Buchbauer, G. (2004). Evaluation of the Harmonizing Effect of Ylang-Ylang Oil on Humans after Inhalation. Planta Medica, 70, 632-636. http://dx.doi.org/10.1055/s-2004-827186

Hongratanaworakit, T., \& Buchbauer, G. (2006). Relaxing Effect of Ylangylang Oil on Humans after Transdermal Absorption. Phytotherapy Research, 20, 758-763. http://dx.doi.org/10.1002/ptr.1950

Kellerova, E., \& Delius, W. (1969). Unterschiede der vasomotorischen reaktivitat im muskel- und akralen hautgefassgebiet der oberen und unteren extremitaten. Zeitschrift fur Kreislaufforschung, 58, 917-925.

Kikuchi, A., Yamaguchi, H., Tanida, M., Abe, T., \& Uenoyama, S. (1992). Effect of Odours on Cardiac Response Patterns and Subjective States in a Reaction Time Task. Tohoku Psychologica Folia, 51, 74-82.

Klemm, W. R., Lutes, S. D., Hendrix, D. V., \& Warrenburg, S. (1992). Topographical EEG Maps of Human Responses to Odors. Chemical Senses, 17, 347-361. http://dx.doi.org/10.1093/chemse/17.3.347

Kling, J. W., \& Riggs, L. A. (1972). Experimental Psychology. New York: Holt, Reinhart and Winston.

Kyle, G. (2006). Evaluating the Effectiveness of Aromatherapy in Reducing Levels of Anxiety in Palliative Care Patients: Results of a Pilot Study. Complementary Therapies in Clinical Practice, 12, 148-155. http://dx.doi.org/10.1016/j.ctcp.2005.11.003

Lang, P. J., Bradley, M. M., \& Hamm, A. O. (1998). Emotion and Motivation: Measuring Affective Perception. Journal of Clinical Neurophysiology, 15, 397-408. http://dx.doi.org/10.1097/00004691-199809000-00004

Lawless, H. T., \& Heymann, H. (1988). Sensory Evaluation of Food: Practices and Principals. New York: Chapman and Hall.

Leitereg, T. J., Guadagni, D. G., Harris, J., Mon, T. R., \& Teranishi, R. (1971). Chemical and Sensory Data Supporting the Difference between the Odors of the Enantiomeric Carvones. Journal of Agricultural and Food Chemistry, 19, 785-787. http://dx.doi.org/10.1021/jf60176a035

Li, W., Howard, J. D., Parrish, T. B., \& Gottfried, J. A. (2008). Aversive Learning Enhances Perceptual and Cortical Discrimination of Indiscriminable Odor Cues. Science, 319, 1842-1845. http://dx.doi.org/10.1126/science.1152837

Linkert, R. (1932). A Technique for the Measurement of Attitudes. Archives of Psychology, 140, 44-53.

Lledo, P.-M., Gheusi, G., \& Vincent, J.-D. (2005). Information Processing in the Mammalian Olfactory System. Psysiological Reviews, 85, 281-317. http://dx.doi.org/10.1152/physrev.00008.2004

Lorig, T. S., \& Schwartz, G. E. (1988). Brain and Odor: I. Alteration of Human EEG by Odor Administration. Psychophysiology, 16, 281-284.

Manley, C. H. (1993). Psychophysiological Effect of Odor. Critical Reviews in Food Science and Nutrition, 33, 57-62. http://dx.doi.org/10.1080/10408399309527612

Mehrabian, A., \& Russell, J. A. (1974). An Approach to Environmental Psychology. Cambridge, MA: MIT Press. 
Meilgaard, M. C., Giville, G. V., \& Carr, B. T. (1999). Sensory Evaluation of Techniques (3rd ed.). Boca Raton, FL: CRC Press. http://dx.doi.org/10.1201/9781439832271

Mombaerts, P. (1999). Molecular Biology of Odorant Receptors in Vertebrates. Annual Review of Neuroscience, 22, 487-509. http://dx.doi.org/10.1146/annurev.neuro.22.1.487

Morris, E. T. (1984). Fragrance. New York: Scribners.

Ohloff, G., \& Klein, E. (1962). Die absolute konfiguration des linaloolsdurchverknuepfungmitdempinansystem. Tetrahedron, 18, 37-42.

Oka, T., Hayashida, S., Kaneda, Y., Takenaga, M., Tamagawa, Y., Tsuji, S., \& Hatanaka, A. (2008). Green Odor Attenuates a Cold Pressor Test-Induced Cardiovascular Response in Healthy Adults. BioPsychoSocial Medicine, 2, 2. http://dx.doi.org/10.1186/1751-0759-2-2

Oka, T., Oka, K., \& Hori, T. (2001).Mechanisms and Mediators of Psychological Stress-Induced Rise in Core Temperature. Psychosomatic Medicine, 63, 476-486. http://dx.doi.org/10.1097/00006842-200105000-00018

Perry, N., \& Perry, E. (2006). Aromatherapy in the Management of Psychiatric Disorders: Clinical and Neurophamacological Perspectives. CNS Drugs, 20, 257-280. http://dx.doi.org/10.2165/00023210-200620040-00001

Price, S., \& Price, L. (2007). Aromatherapy for Health Professionals (3rd ed.). London: Elsevier.

Raudenbush, B., Grayhem, R., Sears, T., \& Wilson, I. (2009). Effects of Peppermint and Cinnamon Odor Administration on Simulated Driving Alertness, Mood and Workload. North American Journal of Psychology, 11, 245-256.

Roddie, I. C. (1983). Circulation to Skin and Adipose Tissue. In J. T. Shepard, \& F. M. Abbound (Eds.), Handbook of Physiology. The Cardiovascular System (Vol. II, Part 1, Chapter 10, pp. 285-317). Bethesda, MD: American Physiological Society,.

Roddie, I. C., Shepherd, J. T., \& Whelan, R. F. (1957). The Contribution of Constrictor and Dilator Nerves to the Skin Vasodilatation during Body Heating. The Journal of Physiology, 136, 489-497. http://dx.doi.org/10.1113/jphysiol.1957.sp005775

Roderick, W. R. (1966). Current Ideas on the Chemical Basis of Olfaction. Journal of Chemical Education, 43, 510-520. http://dx.doi.org/10.1021/ed043p510

Rowell, L. B. (1981). Active Neurogenic Vasodilation in Man. In P. M Van Houtte, \& I. Leusen (Eds.), Vasodilation (pp. 1-17). New York: Raven Press.

Russell, G. F., \& Hills, J. I. (1971). Odor Difference between Enantiomeric Isomers. Science, 172, 1043-1044. http://dx.doi.org/10.1126/science.172.3987.1043

Satoh, T., \& Sugawara, Y. (2003). Effects on Humans Elicited by Inhaling the Fragrance of Essential Oils: Sensory Test, Multi-Channel Thermometric Study and Forehead Surface Potential Wave Measurement on Basil and Peppermint. Analytical Sciences, 19, 139-146. http://dx.doi.org/10.2116/analsci.19.139

Smallwood, J., Brown, R., Coulter, F., Irvine, E., \& Copland, C. (2001). Aromatherapy and Behaviour Disturbances in Dementia: A Randomized Controlled Trial. International Journal of Geriatric Psychiatry, 16, 1010-1013. http://dx.doi.org/10.1002/gps.473

Stevens, S. S. (1951). Handbook of Experimental Psychology. New York: John Wiley.

Sugawara, Y. (2001). Odor Distinctiveness between Enantiomers of Linalool. Current Topics in Analytical Chemistry, 2, 201-210.

Sugawara, Y. (2008). Sensory Profiling for Verbal Responses in Perceived Odor Quality in Humans. In L. N. Piccard (Ed.), Biological Psychology: New Research (Chapter 4, pp. 145-165). New York: Nova Science Publishers.

Sugawara, Y., \& Kawasaki, M. (2000). Skin Temperature Change Elicited by Inhalation of the Fragrance of Essential Oils in Relation to Mental Work: Multi-Channel Thermometric Study on Basil and Peppermint. Journal of Home Economics of Japan, 51, 675-681.

Sugawara, Y., Fukui, H., Shigeoka, C., Hasegawa, R., \& Okimoto, A. (2006). Multichannel Thermometric Study of Skin Temperature Changes in Humans While Inhaling Essential Oils. Flavour and Fragrance Journal, 21, 416-422. http://dx.doi.org/10.1002/ffj.1683

Sugawara, Y., Hara, C., Aoki, T., Sugimoto, N., \& Masujima, T. (2000). Odor Distinctiveness between Enantiomers of Linalool: Difference in Perception and Responses Elicited by Sensory Test and Forehead Surface Potential Wave. Chemical Senses, 25, 77-84. http://dx.doi.org/10.1093/chemse/25.1.77

Sugawara, Y., Hara, C., Tamura, K., Fujii, T., Nakamura, K., Masujima, T., \& Aoki, T. (1998a). Sedative Effect on Humans of Inhalation of Essential Oil of Linalool: Sensory Evaluation and Physiological Measurements Using Optically Active Linalools. Analytica Chimica Acta, 365, 293-299. http://dx.doi.org/10.1016/S0003-2670(97)00639-9

Sugawara, Y., Hino, Y., Kawasaki, M., Hara, C., Tamura, K., Sugimoto, N., Yamanishi, U., Miyauchi, M., Masujima, T., \& 
Aoki, T. (1999). Alteration of Perceived Fragrance of Essential Oils in Relation to Type of Work: A Simple Screening Test for Efficacy of Aroma. Chemical Senses, 24, 415-421. http://dx.doi.org/10.1093/chemse/24.4.415

Sugawara, Y., Maruyama, S., Nakagawa, N., Yamada, E., Seto, M., Sumihiro, S., Aoi, N., Nishimoto, M., Kobayashi, Y., \& Hirano, M. (2008). Verbal and Non-Verbal Responses to Odorants in Humans While Inhaling the Fragrance of Peppermint and Spearmint Essential Oils and Linalool. International Journal of Essential Oil Therapeutics, 2, 111-121.

Sugawara, Y., Nishimoto, M., Kobayashi, Y., Hasegawa, R., Okimoto, A., \& Aoki, T. (2003). Repeatability of the Measure Required for Perceptional Changes of the Fragrance of Essential Oils Was Tested in Terms of Sensory Evaluation Spectrums. Bull. Fac. Human Life Environ. Sci. Hiroshima Women's Univ., 9, 21-36.

Sugawara, Y., Shigetho, A., Yoneda, M., Tuchiya, T., Matumura, T., \& Hirano, M. (2013). Relationship between Mood Change, Odour and Its Physiological Effects in Humans While Inhaling the Fragrances of Essential Oils as Well as Linalool and Its Enantiomers. Molecules, 18, 3312-3338. http://dx.doi.org/10.3390/molecules18033312

Sugawara, Y., Sugimoto, C., \& Minabe, S. (2009b). Sensory Evaluation of the Deodorizing Efficacy of a Titanium Oxide-Type Deodorant. Journal of Home Economics of Japan, 60, 353-362.

Sugawara, Y., Sugimoto, C., Minabe, S., Iura, Y., Okazaki, M., Nakagawa, N., Seto, M., Maruyama, S., Hirano, M., \& Kitayama, I. (2009a). Use of Human Senses as Sensors. Sensors, 9, 3184-3204. http://dx.doi.org/10.3390/s90503184

Sugawara, Y., Tomota, T., \& Tamura, K. (1998b). Perceived Fragrance of Essential Oils in Relation to Type of Work. Journal of Home Economics of Japan, 49, 1281-1290.

Torgerson, W. S. (1958). Theory and Methods of Scaling. New York: John Wiley.

Torii, S., Fukuda, H., Kanemoto, H., Miyauchi, R., Hamauzu, Y., \& Kawasaki, M. (1988). Contingent Negative Variation and the Psychological Effects of Odour. In S. van Toller, \& G. H. Dodd (Eds.), Perfumery: The Psychology and Biology of Fragrance (pp. 107-120). New York: Chapman Hall. http://dx.doi.org/10.1007/978-94-017-2558-3_6

Vallbo, A. B., Hagbarth, K.-E., Torebjork, H. E., \& Wallin, B. G. (1979). Somatosensory, Proprioceptive and Sympathetic Activity in Human Peripheral Nerves. Physiological Reviews, 59, 919-957.

Valnet, J. (1982). The Practice of Aromatherapy. Saffron Walden, MA: C W Daniel Company.

Yamagata, Y., \& Sugawara, Y. (2014). Sensory Evaluation Spectrum Method as a Descriptive Sensory Analysis. Psychology, 5, 1591-1610. http://dx.doi.org/10.4236/psych.2014.514170

Yamaguchi, H. (1990). Effect of Odor on Heart Rate. In M. Indo (Ed.), The Psychophysiological Effects of Odor, Aromachology (p. 168). Tokyo: Koryo.

Yamakoshi, T., Yamakoshi, K., Tanaka, S., Nogawa, M., Shibata, M., Sawada, Y., Rolfe, P., \& Hirose, Y. (2007). A Preliminary Study on Driver's Stress Index Using a New Method Based on Differential Skin Temperature Measurement. 29th Annual International Conference of the IEEE Engineering in Medicine and Biology Society, Lyon, 22-26 August 2007, 722-725. http://dx.doi.org/10.1109/iembs.2007.4352392

Yoshida, I., \& Mori, K. (2007).Odorant Category Profile Selectivity of Olfactory Cortex Neurons. The Journal of Neuroscience, 27, 9105-9114. http://dx.doi.org/10.1523/JNEUROSCI.2720-07.2007

Zhang, X., \& Firestein, S. (2002).The Olfactory Receptor Gene Superfamily of the Mouse. Nature Neuroscience, 5, $124-133$.

Ziegler, L. H., \& Cash, P. T. (1938). A Study of the Influence of Emotions and Affects on the Surface Temperature of the Human Body. The American Journal of Psychiatry, 95, 677-696. http://dx.doi.org/10.1176/ajp.95.3.677 